\title{
LA FACULTAD DE TEOLOGÍA DE LA UNIVERSIDAD DE ALCALÁ: VISITAS Y ESTADO DE CÁTEDRAS ENTRE 1524 Y 1545
}

\author{
POR \\ GONZALO GÓMEZ GARCíA ${ }^{1}$ \\ Universidad de Alcalá \\ Instituto universitario de estudios medievales y del siglo de Oro Miguel de Cervantes
}

\begin{abstract}
RESUMEN
Cisneros dejó establecidas las visitas de cátedras en las constituciones fundacionales de la Universidad de Alcalá como mecanismos para controlar y mejorar la calidad docente. Por ello, nos proponemos analizar las actas de las visitas conservadas desde 1524 hasta 1545 para conocer el estado de las regencias y el pulso estudiantil de la Facultad de Teología en los primeros años desde la muerte del fundador. Pero también estableceremos las relaciones de poder generadas en la jerarquía de la facultad con agentes internos y externos a la universidad, cuya principal consecuencia será el bajo interés que suscitó la teología complutense antes de Trento.
\end{abstract}

PALABRAS CLAVE: Universidad de Alcalá; Facultad de Teología; cátedras; regentes; santo Tomás; nominales; Escoto.

\section{THE FACULTY OF THEOLOGY OF THE UNIVERSITY OF ALCALÁ: VISITS AND STATUS OF CHAIRS BETWEEN 1524 AND 1545}

\begin{abstract}
Cisneros established the visits of chairs in the founding constitutions of the University of Alcalá as mechanisms to control and improve the teaching quality. For this reason, we propose to analyze the minutes of the visits conserved from 1524 to 1545 to know the state of the regencies and the student pulse of the faculty of Theology in the first years from the death of the founder. But we will also establish the power relations generated in the hierarchy of the faculty with internal and external agents to the university, whose main consequence will be the low interest aroused by Complutense's theology before Trent.
\end{abstract}

KEY WORDS: University of Alcalá; faculty of Theology; chairs; regents; saint Thomas; Ockham; Scoto.

Cómo CITAR este artículo / Citation: Gómez García, Gonzalo. 2019. "La Facultad de Teología de la Universidad de Alcalá: visitas y estado de cátedras entre 1524 y 1545». Hispania Sacra 71, 144: 439-454. https://doi.org/10.3989/hs.2019.031

$\begin{array}{ll}\text { Recibido/Received } & \text { 04-01-2018 } \\ \text { Aceptado/Accepted } & 12-06-2018\end{array}$

LAS FUENTES DE LAS VISITAS DE CÁTEDRA Y PROPUESTA DEL MÉTODO HISTÓRICO

Las fuentes utilizadas en el presente análisis son las actas de las visitas de cátedras en la Universidad de Alcalá. La problemática que presenta el archivo universitario complutense en la primera mitad del XVI es su evidente estado deslavazado, consecuencia de su traslado a Madrid en $1841 .^{2} \mathrm{El}$

1 gonzalodegomez@yahoo.es /

ORCID iD: https://orcid.org/0000-0001-8827-3609

2 Sobre el traslado del archivo y biblioteca complutense a Madrid entre 1841 y 1843 véase Fernández 2001: 377-401; Hernández Sandoica y Peset 1993: 158-159. primer curso en el que quedan registradas es $1523-1524$ y se encuentra en Papeles varios sobre la Universidad y colegios de Alcalá I, AHN, Universidades, Libro $1222 \mathrm{~F}^{3}$ el curso 15241525 en Papeles varios sobre la Universidad y colegios de Alcalá II, AHN, Universidades, Libro 1223F, Cartas al cardenal Cisneros, AHN, Universidades, Libro 1224F y Legajo 65; para el curso 1527-1528 en los citados AHN, Universidades

3 Registro de estudiantes de la "cátedra terminista partido mediano" en Papeles varios sobre la Universidad y colegios de Alcalá, I, AHN, Universidades, Libro $1222 F$, folio 61r, texto en García Oro y Portela Silva 2006: 685. Probablemente la Física de Aristóteles -tercer curso de Arte y Filosofía- explicada según la lógica del nominalismo. 
Libros $1222 \mathrm{~F}$ y $1223 \mathrm{~F}$; los cursos entre 1531 y 1541 en Visitas de cátedras, AHN, Universidades, Legajo 65, Expediente 1; el curso 1542-1543 en Constituciones latinas, oposiciones a cátedras, certificados de cursos, visitas de cátedras, AHN, Universidades, Legajo 755 y el curso 1543-1545 de nuevo en AHN, Universidades, Legajo 65, Expediente 1. El libro que recoge todos los ejercicios y sermones obligatorios teológicos entre 1520-1545, está en Libro de actos de la Facultad de Teología, AHN, Universidades, Libro 396F, íntegro en latín. Las oposiciones a cátedra se conservan, algunas, en los legajos del AHN, Universidades, 754, 755 y 756, sin foliar, posteriores a 1530 aunque en su mayor parte desde 1549. El libro de actos y grados de todas las facultades de la Universidad de Alcalá para nuestro período de estudio se conserva en Libro de actos y grados 1523-1544, AHN, Universidades, Libro 397F. El libro de claustros plenos conservado se inicia en $1556,{ }^{4}$ fuera de nuestro estudio.

Los documentos no presentan una estructura de acta de escribanía formal, ${ }^{5}$ como los conservados en Registro de escrituras ante los escribanos contadores de la hacienda y rentas del Colegio de San Ildefonso y Universidad de Alcalá, AHN, Universidades, Libros, 2, 3 y 4. Cada visita de cátedra está escrita en letra procesal y encabezada con una sencilla data junto al nombre de los cuatro visitadores que la efectúan. A continuación, se recogen los testimonios de los oyentes bajo el nombre del regente o de la cátedra. En estas actas apenas se usan nexos y las escasas fórmulas que aparecen son "In Laudem», "Ut supra in Laudem» o el sencillo "dixo lo mismo». En todo caso, los oyentes acompañan tras su nombre la abreviatura "testigo jurado», "aviendo jurado» o "testigo». Las actas no están firmadas por los visitadores ni refrendadas las declaraciones. Invita a pensar, por tanto, que son meros apuntes de los escribanos del colegio de San Ildefonso, ${ }^{6}$ analizados posteriormente por los visitadores ordinarios enviados desde la colegiata de San Justo. Solo así, en caso de apercibimiento o de sanción a un regente, tendrían validez jurídica al encontrarse en los mandatos de la visita ordinaria, firmada por el visitador, escribano, rector y los consiliarios.

Como complemento a nuestro estudio, se encuentran las actas de las visitas ordinarias para conocer si las particularidades de las cátedras estuvieron reflejadas en sus actas. Las ordinarias ${ }^{7}$ eran efectuadas por los canónigos y beneficiados de la colegiata de San Justo a la Universidad de Alcalá ${ }^{8}$ y en las cuáles debían constar las deficiencias - si las hubierade las visitas de cátedra. Actualmente se encuentran en

\footnotetext{
4 Libro de claustros, AHN, Universidades, Libro 1126.

5 Sobre escribanos universitarios, véase Rodríguez Suárez 2003. Del oficio de escribano en el siglo XVI, Moreno Trujillo 2011.

6 Los escribanos de este período son: Pedro González de Madrid entre 1524 y 1536; Juan de Ayllón entre 1536 y 1545, que continuó hasta 1572.

7 Estas visitas ordinarias están editadas en García Oro y Portela Silva 2006, que adjuntan una transcripción de las visitas rectorales/de cátedras pero solo entre 1523 y 1528. Desde 1528 hasta 1545 la transcripción es nuestra sobre las fuentes indicadas en el presente estudio.

8 Aunque por constituciones debe elegirse por visitador a un canónigo - doctor de la Facultad de Teología o maestro en la Facultad de Artes si fue elegido sin otros opositores teólogos - o un beneficiado de las nuevas prebendas solicitadas por Cisneros, lo cierto es que para nuestro período solo se eligieron canónigos teólogos y por tanto la Facultad de Teología era la mejor posicionada para controlar la Universidad.
}

los manuscritos Libro de cuentas de frutos, rentas y gastos 1524-1530 y 1530-1536, AHN, Universidades, Libros 747F y 748F, Bulario Complutense, III, AHN, Universidades, L.1097F y Papeles varios sobre la Universidad y colegios de Alcalá II AHN, Universidades, L.1223F (folios 116r-117v) y en los legajos de Visitas AHN, Universidades, 65-48, 555-1 y Escrituras de arrendamiento y venta de casas y de imposición, AHN, Universidades, 752. Las instrucciones a los visitadores ordinarios en el citado AHN, Universidades, Legajo 65-2, sin foliar.

Como método de aproximación para conocer la situación académica y sociopolítica de la Universidad de Alcalá en el siglo XVI, creemos adecuado el análisis a través de sus facultades, ${ }^{9}$ línea historiográfica de la que apenas existen investigaciones. ${ }^{10}$ En todo caso, las que hay merecen revisarse desde una perspectiva de observación global de la institución. El método histórico utilizado en los trabajos que se han efectuado sobre la institución cisneriana en los últimos años proviene de la profunda influencia de la historiografía salmanticense de los colegios universitarios como entes independientes. ${ }^{11}$ Línea que, en Alcalá, solo es susceptible de ser utilizada en la fundación y forma de los colegios -el esqueleto universitario-, pero creemos que resulta poco práctica si nuestro interés se centra en el análisis tanto de la situación académica como en lo político-social -órganos vitales y músculo de la institución cisneriana-, que es nuestro objetivo.

Con este método de aproximación que planteamos podemos estudiar tanto el sistema académico como el político-social: las facultades otorgaban títulos, organizaban claustros, facilitaban las promociones y las actas de sus visitas nos dan una respuesta de la calidad de la enseñanza, de sus lecturas, de los regentes, es decir el propio fin de esta universidad. Y en estas facultades también podían $-\mathrm{y}$ lo hicieron- formar redes clientelares.

Es necesario recordar aquí que la institución que controlaba a la Universidad de Alcalá era la colegiata de San Justo a través de los visitadores y de la figura del abad-canciller.

9 Fueron cinco las establecidas en las Constituciones fundacionales: Teología, Arte y Filosofía, Medicina, Derecho Canónico y Gramática. Esta última es la única que no concedía títulos. Cabe destacar que el profesor de investigación Dr. Alfredo Alvar ya indicó en 2010 la necesidad de un cambio en la historiografía de la Universidad de Alcalá (Alvar Ezquerra 2010).

10 Las monografías de las facultades complutenses: Teología en Beltrán de Heredia 1974, con base en los estudios de 1914-1916; de Arte y Filosofía en Urriza 1941; de Medicina en Muñoyerro 1945. Los tres autores citados siguen, sin embargo, la línea historiográfica de las órdenes religiosas respecto al método de análisis. El clásico estudio del gran historiador Torre y del Cerro 1925, nos ofrece una primera una aproximación a las visitas de cátedras en Alcalá de todas las facultades entre 1524 y 1528, aunque las conclusiones sobre los regentes - buenos, malos, regulares - son en cierto modo elementales para el diligente investigador. Gutiérrez Torrecilla (2014: 72) sigue a Antonio de la Torre e indica que las visitas las efectuaban dos colegiales que «elaboraban un informe que presentaban al rector» y no cuatro visitadores -incluyendo rector - como constatamos en el presente estudio. Asimismo, este historiador indica como conclusión que «se extrae de estas visitas que había profesores de todo tipo, buenos, malos y regulares; apreciados o criticados; cumplidores o poco serios».

11 La última publicación sobre la Universidad de Alcalá que sigue aún esta línea historiográfica analizando los colegios menores de forma autónoma sin tener en cuenta el gran universo de estudiantes libres vinculados a las facultades es el de Casado Arboniés y Román Pastor 2017. 
Pero existe un matiz no analizado hasta ahora: esos visitadores de la colegiata eran, a su vez, miembros de la Facultad de Teología o de la de Artes y Filosofía, y, por tanto, la Universidad de Alcalá estuvo controlada por una u otra facultad -los órganos vitales de nuestra metáfora-. Así, insistimos, cada colegio de Alcalá ha sido estudiado sin tener en cuenta que dependía académicamente de una estructura matriz, que no era San Ildefonso - gobierno colegial-, sino cada una de las facultades recogidas en constituciones y en las cuáles los estudiantes de los colegios debían matricularse. Y también los de los pupilajes, los de cámaras alquiladas o los que malvivían en patios comunes por toda Alcalá. El esquema de la Facultad de Teología de Alcalá que vemos en el Cuadro 1 puede aclararnos el origen de los estudiantes y colegiales que la integraban.

\section{CUADRO 1}

Estructura de la Facultad de Teología según propuesta historiográfica: aulas y colegios adscritos a ella

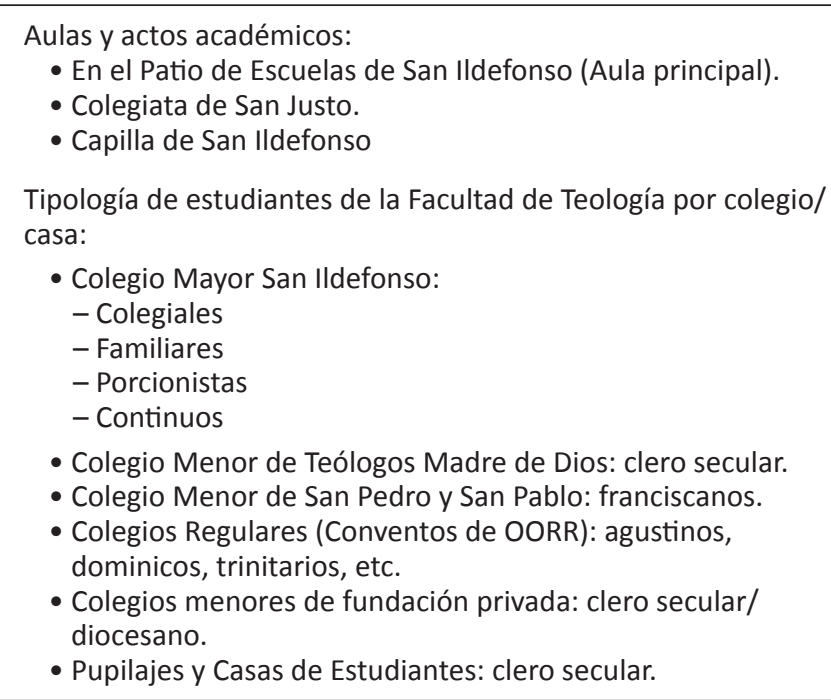

Fuente: elaboración propia.

\section{TEORÍA: EL MARCO CONSTITUCIONAL}

Cisneros, celoso siempre de la excelencia humana para el éxito de su fundación, dejó plasmadas en las constituciones de $1510^{12}-\mathrm{y}$ revisadas poco antes de su muerte en 1517el control periódico de la institución universitaria mediante la constitución 63 De visitatione Collegii, en la que se estipula y vertebra la visita ordinaria de un prebendado de la colegiata de San Justo a la Universidad de Alcalá. Este visitador canónico tendría que recopilar tanto la visita del curso precedente, como las cuentas de los oficiales y el estado particular de personas, así como la administración de gastos y prebendas de los colegios universitarios que dependían del Mayor. El visitador ordinario no efectuaba las particulares visitas de cátedras, sino que era informado por los visitadores elegidos para dicha empresa. Estos eran dos: el rector y uno los tres consiliarios del colegio de San Ildefonso -cargos administrativos, por tanto, un colegial del Mayor junto al rector-y dos de los consiliarios de la Universidad-cargos

12 Constituciones latinas originales, AHN, Universidades, L. 1.085F y las reformadas de 1517 en Constituciones latinas originales, AHN, Universidades, L. 674F. claustrales, por tanto, dos estudiantes que fueran al menos bachilleres en Artes y estuvieran vinculados a una facultad-, para realizar estas visitas a las aulas según la constitución 35 De electione regentium et lectorum. En esta constitución se indica, al final, su desempeño al investigar

cómo se comportaron los regentes y catedráticos y lectores de aquel colegio en leer y regir sus cátedras y lecturas, y acerca de la abundancia o penuria de los oyentes. Y así informado, si viese algún defecto respecto a las predichas cosas, provea la necesidad y a la utilidad del mismo colegio y universidad. De tal suerte que en manera alguna sufran detrimento el colegio o los oyentes respecto de la doctrina y respecto de las lecciones, según se previene en la predichas y en otras constituciones.

El ordenamiento de las visitas de cátedras sería complementado con la constitución 65 , en la que se confirma que los consiliarios de esta universidad - aquellos estudiantes que moraban fuera del colegio de San Ildefonso ${ }^{13}$ - apoyarían a los dos elegidos entre el rector y los consiliarios colegiales para realizar las restantes visitas a las aulas. Todo ello estaría epilogado en unas interesantes y claras instrucciones en De forma per visitatorem ecclesie sanctorum lusti et Pastoris in visitatione collegii observanda, ${ }^{14}$ un texto fuera del código fundacional cisneriano, fechado ca. 1517. En este manuscrito se extraen y reúnen directamente todos aquellos mandatos relacionados con las visitas ordinarias y las de cátedras que se encuentran esparcidos por las constituciones fundacionales, buscando un fin no exento de pragmatismo. ${ }^{15}$ Por tanto, creemos que es muy probable que Cisneros estuviera detrás de estas instrucciones precisamente cuando en la posterior reforma de las constituciones que efectúa en $1517^{16}$ él mismo decida ordenar que la visita ordinaria no se efectúe una vez al año, sino que esta se desdoble en dos: enero y julio. Con este cambio, aumentaba el control de la colegiata de San Justo - y de las facultades de Teología o de Artes - a la Universidad de Alcalá y, por tanto, mermaba la teórica autoridad del rector.

\section{ESTRUCTURA E INTERROGATORIO}

Las actas de visitas de cátedras a la Universidad de Alcalá se conservan desde el curso 1523-1524. Al tratarse de años inmediatamente posteriores a la muerte del fundador (+1517), podemos observar con detalle si la vida académica complutense lograba asentar sus cimientos desde la orfandad. La estructura de esta visita era sencilla ya que se elegían varios testigos por aula (se visitaban todas las cátedras de Teología, Súmulas, Lógica, Física, Metafísica, Matemáticas, Medicina, Gramática griega, gramáticos latinos divididos en menores, medianos y mayores, gramática hebrea, Retórica, Moral y Cánones) los cuáles, en una cámara aparte,

13 Eran un $90 \%$ los estudiantes no colegiales, es decir, no adscritos a colegios ni becados por ellos. Eran estudiantes libres matriculados en las facultades que conformaban un universo al que la historiografía de los últimos años no ha dedicado apenas espacio.

14 Constituciones Colegio Mayor de San Ildefonso y Universidad de Alcalá, AHN, Universidades, Libro 1085F, folios 64r-68v.

15 lb. Folio 64v con texto extraído de la constitución 35.

16 Los textos traducidos al castellano de las constitucionales de Cisneros de 1510 y 1517 en González Navarro 1984: 348-385. 
procedían a contestar un interrogatorio sobre los regentes de cada cátedra. El fin fue garantizar la calidad de la enseñanza - verdadera preocupación de Cisneros- y detectar errores que, de otra forma, hubieran sido difíciles de hallar. Este interrogatorio constaba de las siguientes preguntas: ${ }^{17}$

1. Si entran a tiempo a leer y están todas las horas enteras o más que han de estar leyendo y es algún inconveniente leer más de los que han de leer y si faltan algunos días.

2. Si hacen los ejercicios que manda la constitución que son reparaciones y conclusiones y cuestiones, si preguntan a los oyentes.

3. Si hacen provecho a los oyentes y ellos aprovechan en su lectura y si están contentos del catedrático y le tiene por idóneo y suficiente.

4. Si han acabado los libros que son obligados a leer y en el tiempo que son obligados.

5. Si son pocos o muchos los oyentes para según es la lectura y el tiempo y los estudiantes.

6. Si hay algún daño o defecto u otra cosa alguna que se haya de proveer o corregir.

De las actas de estos interrogatorios tomaban nota los visitadores ordinarios para considerar una posible sanción que enmendase las faltas de los regentes. Por ello, es frecuente observar apostillas marginales en todas las actas de las visitas de cátedra con el vocablo "ojo» justo en la línea en la que se describía una falta. Incluso podrían subrayar una falta si esta era clamorosa.

Evitando una interpretación desde el probabilismo, las declaraciones de los estudiantes creemos que son extraordinariamente claras, toda vez que se trata de textos sin ambages en los que los protagonistas -los oyentesexpresan sus opiniones con el único fin que había entonces: progresar en la ciencia. Todo aquello que lastrase o mellase este camino, ya de por sí bastante sinuoso, tendría que ser denunciado.

Sin embargo, tanto el texto constitucional como las instrucciones posteriores fueron extremadamente laxas con el hallazgo de regentes con pocas facultades para la enseñanza. Según la constitución 35, en caso de existir este mal se pretendía curar únicamente mediante meras multas de retención de salarios que no tuvieron efecto alguno para inspirar a los regentes pésimos o perezosos. Pudo conllevar la pérdida de la cátedra, pero nunca fue así, al menos en este período y con algunos regentes claramente inanes.

Nuestro estudio se va a centrar, por tanto, en el análisis de las visitas de aulas en la Facultad de Teología.

La Facultad de Teología de la Universidad de Alcalá y SU ESTRUCTURA CLAUSTRAL: DECANO, DOCTORES Y REGENTES TEÓLOGOS

La facultad teológica de la Universidad de Alcalá18 es citada en la constitución fundacional 43 como aquella de la

17 Visitas de aulas y de cátedras, AHN, Universidades, Legajo 65-2, s. f.

18 Respecto al análisis de las facultades complutenses, la historiografía de la Universidad de Alcalá es aún escasa o bien se trata de estudios que han de ser revisados. Sobre la Facultad de Teología complutense Beltrán de Heredia 1974: 61-123 (hasta la p. 87 es una introducción al que formarán parte las tres cátedras magistrales de Santo Tomás, Escoto y Nominales «tantas como vías seguidas en las escuelas en estos tiempos». Se trata, por tanto, de una institución académica sin construcción física independiente, ya que las aulas se situaron en el Mayor de San Ildefonso, el claustro se reunió en la Capilla y sacristía de San Ildefonso y los exámenes se efectuaron en el Teatro (hoy paraninfo), en el trascoro de la Colegiata de San Justo. También hubo exámenes en la capilla del Mayor, en la que también se hicieron los sermones de los estudiantes teólogos. La toma de cátedras se efectuó en la Capilla y en la sacristía de San Ildefonso y luego se confirmaba la posesión con una clase magistral en el aula subiéndose a la cátedra.

\section{CUADRO 2}

Estructura de la Facultad de Teología de la Universidad de Alcalá

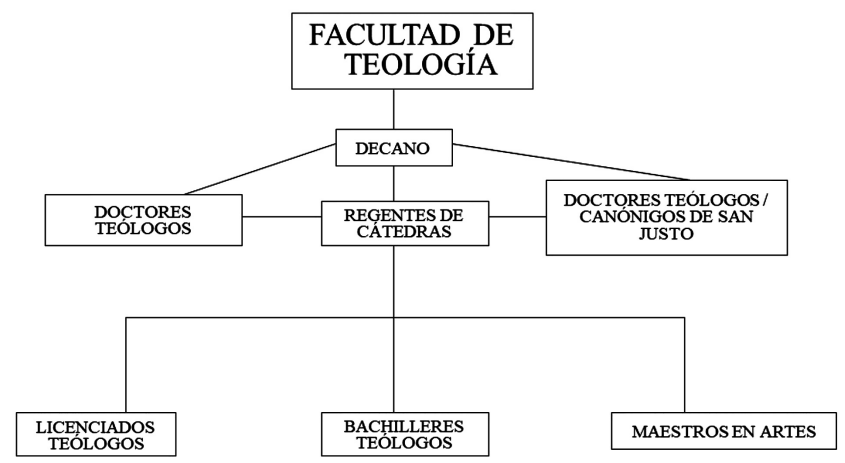

Fuente: elaboración propia.

En el Cuadro 2 presentamos la estructura de Facultad de Teología de la Universidad de Alcalá. Los estudiantes podían ser: de los primeros cuatro años (maestros en Artes), entre 4 y 7 años (ya bachilleres teólogos) y 8 o año (licenciados teólogos). En las constituciones de 1510 se establecen ocho años para las regencias teológicas. Son regencias de cátedras ya que no eran en propiedad, De ahí que la denominación usada entonces para los lectores sea el de regentes. Podían volver a opositar al finalizar la regencia. En 1517 Cisneros redujo el tiempo de lectura de cátedra a cuatro años y modificó la estructura de esta facultad. Así, en la constitución 44 de 1517 , se indica expresamente la jerarquía al detallar que «será siempre decano, tanto en Teología como en las otras facultades, el doctor o maestro más antiguo en el grado en aquella facultad que en todas las cosas debe preceder a

estudio de la teología en las universidades castellanas). Heredia aporta la primera transcripción de algunas visitas de cátedras teológicas, pero no todas, sino pocas y sesgadas. En todo caso siguiendo siempre su línea historiográfica en la que hace hincapié que el éxito de la institución complutense se habría asegurado con más peso del clero regular y no tanto del secular (pp. 96-97) siguiendo el modo salmanticensis. Indica, además, que el peligro principal era que la ortodoxia se perdiera (p. 115) cuando, de hecho, no es hasta Trento cuando se delimitan los campos de la ortodoxia y heterodoxia, dejando Cisneros una institución fundada principalmente en repensar dentro de un estado independiente la Sagrada Ciencia, con un más que probable desinterés por la participación activa de las órdenes mendicantes, salvando su orden franciscana y en todo caso tangencialmente. De otro modo no hubiera ampliado el coro de la colegiata de San Justo para atender a los doctores teólogos y maestros artistas, y hubiera establecido como base un convento-universidad, como en Sevilla y no un colegio-universidad-colegiata, que fue la realización final complutense. 
todos los demás de la misma facultad después del rector ${ }^{19}$ cargo que estuvo ocupado desde 1510 por el regente más antiguo en activo hasta dicha fecha en que pasa al doctor más antiguo sin necesidad de ser regente. Además de los regentes junto al deán o decano estaban los doctores no docentes, los cuáles presidían los actos teológicos, sin obligatoriedad de ser docente en activo ${ }^{20}$ y que eran en su mayoría canónigos de la colegiata de San Justo. Como ejemplo, en 1530 el claustro de la Facultad de Teología lo componía el deán, tres regentes de cátedra y veinte doctores teólogos.

En la constitución 46 se añaden varios aspectos en la reforma de 1517 , entre ellos la capilla anual que debería congregar a la Facultad de Teología por orden del rector, pasada la fiesta de los Santos, en la que se asignaban los actos teológicos a bachilleres y licenciados «de tal modo que, si es posible, no falte cada año toda la diversidad de actos». En la 47 se indica, a su vez, que la Facultad de Teología organice para los bachilleres que hubieran superado los actos el día de sus licencias, en la colegiata de San Justo u otro lugar solemne, así como el doctorado teológico, descrito en la 48. Sobre los cursos obligatorios para conseguir cualquier grado, están descritos entre las constituciones 45-48. Por tanto, tenemos una estructura académica organizada en torno a tres cátedras principales y unos actos académicos presididos por teólogos doctores vinculados bien como regentes en activo, prebendados de San Justo, bien como meros doctores cuya acción principal era participar y fomentar el avance de la teológica. Estos, que normalmente eran sustitutos de los titulares en sus ausencias, pasarán a ocupar las cátedras menores o catedrillas que se irán creando a partir del curso 1536-1537 como parte de la carrera universitaria a las cátedras de Prima.

Todos los claustros estaban presididos por su deán. Hasta 1534 fue Pedro de Lerma quien, a su vez, fue el abad de la colegiata de San Justo, dignidad que tenía la facultad de refrendar los títulos de licenciado, maestro o doctor como canciller universitario en virtud de la bula de Alejandro VI Etsi Cunctos. ${ }^{21}$ Por tanto, en una sola persona no colegial sin posibilidad de ser rector, sin auctoritas, pero sí universitaria, unificó los tres principales cargos del poder complutense: abad de su colegiata, deán de la facultad teológica y canciller universitario, es decir, con plena potestas.

Por último, en el libro de actos de la Facultad de Teología tenemos registrados, además de los actos, ejercicios y sermones, ${ }^{22}$ sus estatutos. No fueron unas leyes o fueros particulares independientes o paralelos a las constituciones de Cisneros. Reunidos el claustro de doctores determinaban establecer o fijar aquellas dudas que puedan surgir en la interpretación de la carta magna de 1517.

\footnotetext{
19 González Navarro 1984: 435.

20 Existe un error en la historiografía reciente en la que se atribuye a la creación de las prebendas nuevas de San Justo a una jubilación de los profesores teólogos o artistas. El acceso a una canonjía nueva estaba reservada a graduados complutenses los cuáles podían acceder a la regencia de cátedra antes o después de ser canónigo, siempre que fueran doctores en Teología por Alcalá. Del mismo modo actuaban los racioneros de San Justo que debían ser maestros en Artes por Alcalá.

21 Bula Etsi Cunctos, AHN, Universidades, Cartulario, 4, n. 2.

22 Cabe destacar la ausencia de actos en el curso 1520-1521 debido a las revueltas comuneras en Alcalá que calaron en una sociedad colegial ya dividida tras la muerte de Cisneros.
}

Destacamos el curso 1526-1527 y el Decretum o Statutum sacrae $T^{e}$ (ologiae) facultatis ${ }^{23}$ en el que hay referencias a la obligación de realizar los sermones latinos por parte de los doctores de esta facultad en la fiesta de los Santos Doctores Jerónimo, Gregorio, Ambrosio y Agustín. Por otro lado, en el curso $1529-1530,{ }^{24}$ se cita la constitución 45 que alude a los cursos de bachilleres. Se establece que han de oírse de forma íntegra cuatro años o cuatro cursos contados desde san Lucas hasta el inicio del curso siguiente. La constitución 46 , que alude a los licenciados, indica el estatuto que el año habrá de haberse hecho previamente la necesaria Tentativa. Aquellos bachilleres que obtuvieron su título sin presidente y sin tentativa pública fueron los llamados «bachilleres corrientes». En el curso 1531-1532 estableció la Facultad de Teología en sus Statutum la limpieza de sangre: ${ }^{25}$ "qui ipse in persona sua vel ex judaísmo vel ex machometismi errore seu gentitlitate ad christianam fidem conversus sit...». El libro de actos no nos deja más añadidos: hasta 1546 no se vuelve a producir otra adenda en los estatutos de la Facultad de Teología, ya fuera de nuestro estudio.

Cabe indicar que los actos recogidos en dicho libro son realizados con perfecta regularidad, salvo el curso 15201521 en que los exámenes fueron suspendidos por los disturbios internos del colegio Mayor, que se avivaron con la llama de los comuneros. ${ }^{26}$

Es interesante destacar que desde 1534, fecha en que fallece el arzobispo Alonso de Fonseca, dejan de controlar la Facultad de Teología Pedro de Lerma, Pedro Ciruelo y Miguel Carrasco pues eran los teólogos más antiguos de la facultad y los más allegados al arzobispo primado, a quien veremos interviniendo en asuntos colegiales por medio de Lerma. ${ }^{27}$ Pedro de Lerma, revisado y denunciado como converso en la investigación de Juan de Vergara, sale de la península para terminar en París. Pedro Ciruelo pasó a una canonjía en Segovia y después a Salamanca; Miguel Carrasco, mano derecha en Alcalá del arzobispo Alonso de Fonseca, fallece poco después. Ninguno, excepto Carrasco, aparece ya en los actos teológicos del curso $1538-1539 .^{28}$ El sucesor como cancelario universitario es el sobrino de Pedro de Lerma, Luis de la Cadena el cual se doctoró en Teología el 27/1/1535, fecha en la que toma el cargo. No es decano, como su tío, ya que no le pertenece por antigüedad siendo este cargo ocupado por Miguel Carrasco

\footnotetext{
${ }^{23}$ Libro de actos y grados, AHN, Universidades, Libro 397F, folios $19-20$

24 Libro de actos de la Facultad de Teología, AHN, Universidades, Libro 396 F, folio $37 \mathrm{v}$.

25 El primer estatuto de limpieza de sangre en Alcalá es temprano, de 1519, ver Estatutos de limpieza de sangre de los neófitos que han de ingresar en el Colegio Mayor como colegiales o capellanes y de los franciscanos del Colegio de San Pedro y San Pablo, AHN, Universidades, Libro 1095, n. 62. folios 127-129. El estatuto fue confirmado por el legado de Clemente VII en 1524, ver AHN, Universidades, Cartulario 15, n. 49 . En 1531 se amplía a los visitadores ordinarios mediante la bula Ex suscepti, AHN, Universidades, Libro 1095, n. 62. Folio 182. En este período no faltan acusaciones, como la efectuada contra Jorge de Naveros en 1528 por Juan Sánchez.

26 Para conocer a fondo el conflicto colegial véase Beltrán de Heredia 1960: 25-59. Sobre los comuneros en Alcalá, últimas aportaciones en Carrasco Tezanos 2016.

27 Como nos adelanta Gómez de Castro 1984, cuando habla de Fonseca y su amistad con Pedro de Lerma.

28 Libro de actos de la Facultad de Teología, AHN, Universidades,
} Libro 396 F, folio 68. 
hasta 1540, firmando con mano trémula una canonjía de San Justo como decano. ${ }^{29}$ Finaliza nuestro periodo como decano Juan de Medina, hasta su muerte en 1546.

\section{LAS VISITAS Y LOS CATEDRÁTICOS HASTA 1545}

De las fuentes conservadas de las visitas de aulas, hemos extraído los testimonios de aquellas referentes a las cátedras teológicas. Como hemos indicado, tres fueron las instituidas por Cisneros: Santo Tomás, Escoto y Nominales. El fundador dejó establecido el poder a los colegiales del Mayor en la constitución 58 para erigir nuevas cátedras según necesidades. Así, en 1532, se creó la importante cátedra de Sagrada Escritura o Biblia y en 1536 las tres menores o catedrillas: menor tomista, menor escotista y Durando. ${ }^{30}$

Como vemos en el Cuadro 1, los oyentes de las aulas teológicas podían ser prebendados del Colegio Mayor de San Ildefonso, que eran 33 por constituciones, ${ }^{31}$ o del Menor de Teólogos de la Madre de Dios, ${ }^{32}$ que disponía de 18 prebendas para estudiantes teólogos. Fuera de prebendas, estaban los porcionistas del Mayor según la constitución 13, en número indeterminado, que no necesitaban beca para sus estudios y a los que se les permitía permanecer en San Ildefonso hasta su magisterio en la Sagrada Ciencia. Podían estudiar la Teología o las Artes. También en el Mayor estaban reconocidos por constituciones los camaristas, recogidos en la constitución 14 , en número máximo de 13, que estarían acompañados por escolares pobres, Ilamados socios, en número indeterminado, aunque generalmente dichos estudiantes estaban destinados al estudio de las Artes, ya que se les exigía al menos haber oído el primer curso de Súmulas para acceder al Mayor como camarista o como socio. Ninguno de los citados hasta aquí podía pertenecer a una orden religiosa. Por otro lado, también asistían a las clases los franciscanos del colegio menor de San Pedro y San Pablo de Alcalá, doce estudiantes prebendados según constitución 24, y los frailes de los colegios-conventos de San Agustín el Real y Santo Tomás de Aquino, en número indeterminado. Aunque según los testimonios de las visitas apenas encontramos un solo fraile dominico testigo en este período. Por último, los estudiantes libres que vivían en patios, cámaras alquiladas, casas de estudiantes o pupilajes esparcidos por Alcalá y que tenían que matricularse para poder realizar testimonios probados de cursos para examinarse y obtener algún grado.

29 Papeles sueltos de cátedras, testimonios de cursos probados, etc. AHN, Universidades, Legajo 754. Sin foliar.

30 Cada colegio-convento de Alcalá de Henares podía incorporar una cátedra nueva, siempre adscrita a la Facultad de Teología. Así, el duque de Lerma fundaría en 1613 dos cátedras tomistas para los dominicos del convento de Santo Tomás complutense: de Prima y de Vísperas, con rentas que administraba el colegio de San Ildefonso quedándose una décima parte en concepto de gastos de administración y cobranza. Véase Alvar Ezquerra 2010a: 337-341. Para un esquema sucinto del resto de cátedras teológicas no instituidas por Cisneros, Beltrán de Heredia 1974: 147-154.

31 Ver constitución 6 para conocer los requisitos a estas prebendas. Destacamos que no podían ser profesos de orden religiosa.

32 Aunque el registro de los colegiales conservados del menor de Teólogos comienza en 1543 en AHN, Libros 1045 al 1051 (Libros de colegiales, de actos literarios, etc.). Este colegio estaba sujeto a las Constituciones de los Colegios pobres de la Universidad de Alcalá, AHN, Universidades, Libro 674, folios 50-56v.
Para nuestro estudio vamos a analizar los testimonios de los estudiantes oyentes, que lógicamente no coinciden con los matriculados. Los oyentes se matriculaban una vez, pero podían asistir a cuántas lecturas de cátedras teológicas quisieran. De ahí que un solo matriculado pueda darnos testimonio de tres o cuatro cátedras diferentes. Si hubiéramos usado la cifra de matrículas, no conoceríamos el éxito o fracaso de las regencias por su concurrencia. Así, en este período, sabemos por las visitas de cátedras que los oyentes de las aulas teológicas en los primeros años de nuestro estudio fueron aproximadamente cien, usando el máximo que tuvo Juan de Medina ya que todos le oían y, a partir de 1536-1537, doscientos e incluso trescientos contando tanto los colegiales prebendados como los estudiantes externos, con el dato de las aulas más concurridas.

Las fuentes manuscritas de las visitas de aulas teológicas nos muestran a cien testimonios registrados para nuestro periodo de estudio. De estos, el número de declaraciones recogidas que hay por acta en un aula teológica está entre tres y doce estudiantes por curso. Podríamos presuponer falta de rigor en las conclusiones de nuestro análisis en el que utilizamos solo una horquilla de interrogados entre el $3 \%$ y el $10 \%$ del total de oyentes. Sin embargo, cabe destacar que casi la mitad de los interrogados, cuarenta y seis, son frailes mendicantes. $Y$, de estos, prácticamente cuarenta son franciscanos. El resto, y siempre que fuera posible, fueron licenciados o bachilleres en la Sagrada Ciencia, es decir con al menos cuatro o seis años de estudios demostrados en las aulas teológicas complutenses, cuatro oyendo a los regentes de las principales cátedras y dos para la Biblia y las Sentencias de Pedro Lombardo. Es decir, se buscó siempre la excelencia por parte de los visitadores, al preferir el testimonio de una orden regular y de la antigüedad de los oyentes para sus interrogatorios.

\section{Cátedra de Nominales}

Es una de las tres cátedras fundadas por el Cardenal Cisneros en las constituciones de 1510. Juan de Medina es el único regente de esta cátedra - cuasi vitalicia - en el presente estudio. Medina comenzaría hacia 1521-1522 a leer la cátedra y se opone, finalmente, en 1524-1525. ${ }^{33}$ Aquí

\footnotetext{
33 No hay constancia exacta de que, como dice Gómez de Castro, Juan de Medina siguiera exactamente a Miguel Carrasco en la de nominales. Entraría oficialmente en su cátedra en 1526 estando todos los cursos anteriores simultaneando las Artes y la enseñanza teológica. Juan de Medina entró colegial en 1516 y probablemente represente el colegial ideal de la constitución treinta y cinco de Cisneros. Entró como regente de Súmulas (primer curso de Artes) en 1518-1519. En 1520 aparece como bachiller en Teología examinándose de Quodlibetos en Libro de actos de la Facultad de Teología, AHN, Universidades, Libro 396 F, folio 1. con fray Clemente presidiendo el acto la prima edomada (sic) septe $^{\text {bis }}$. En mayo de dicho curso realiza el examen de Alfonsina. Acaba el curso licenciado. En esos meses tiene lugar el problema comunero al que se adhiere por pertenencia al grupo de los castellanos. Es magíster hasta 1526 en que obtiene el grado de doctor en Teología. Es por ello que muchos autores indican como fecha más probable de entrada como regente la de 1526 . No aparece paga alguna a Medina hasta el curso 1523-1524. Encontramos además en Libro de memoria del pago de tesoreros, AHN, Universidades, Libro 814, folio 121 que dice que en abril de 1524 aparece una paga como «cathedratico en theologia de la cathedra de nominales» pero probablemente fuera sustituto, pues se conserva el documento de julio de 1525 de la oposición de Juan de Medina a la
} 
permanecerá hasta 1545 (falleció al año siguiente) sin dejar las aulas, incluso realizando visitas ordinarias en su calidad de canónigo de San Justo. ${ }^{34}$ A tenor de las visitas de aulas Juan de Medina fue, hasta la llegada de los teólogos que participaron en Trento y que casi en su totalidad pertenecieron al período último del presente estudio, el de más valía que tuvo Alcalá, tratándolo con excelencia Alvar Gómez. ${ }^{35}$ En sus visitas de cátedras se destacó que los estudiantes lo tenían muy claro con él: frases cortas que decían todo: «no hay más que decir», "lee muy bien» o "están todos contentos». Aunque como faltas principales $-y$ frecuentesindicadas por los estudiantes eran que estaba enfermo y faltaba. Así, en el curso 1525-1526 el maestro Requena dijo que está contento pero que falta por «estar enfermo o tener claustro». Alonso Martínez ${ }^{36}$ dijo que está contento de él y de su lectura; Martín Malo, colegial del Mayor y futuro regente, dijo que "está contento». El padre fray Luis dijo que "está contento, aunque falta algunas horas», al igual que fray Martín de Zúñiga. Fray Francisco de Tavera dijo que "desde San Lucas ora continua bien sus liçiones aunque haze algunas faltas e que no conoce su sust.uto». Fray Antonio de los Ángeles dijo que «muchas veces no acaba la ora porque fácilmente sy le patean para que acabe dexa de leer» y el maestro Requena dijo que «está contento pero que falta por estar enfermo o tener claustro». Jerónimo de Sandoval dijo que "está contento pero que falta muchas veces por indisposición».

En el curso 1527-1528 Francisco Martínez, colegial del Mayor, dijo de él «que está contento e que hace algunas faltas no leyendo», por lo que los visitadores indicaron en apostilla «que procure no faltar dia nynguno el doctor Medina y tenga por sostituto al doctor Moratel». Fray Nufeo dijo «que no oye ni a Santo Tomás, porque no hay nadie, ni a Escoto porque no le gusta el regente. Que sólo asiste a la de Nominales porque está muy contento con el regente y que tendrá unos 100 oyentes». Fray Juan de Quinconces -el estudiante más crítico como veremos en el estudio de las visitas a la cátedra tomista - dijo que está muy contento. En el curso 1531-1532 tenemos solo dos testimonios, el del maestro Gabriel Manrique quien dijo del aula del doctor Medina «suele haber hasta ciento oyentes» y Diego de Góngora «dijo que no hay falta en Medina». En el curso siguiente, 1532-1533, fray Antonio Álvarez «dijo que lee

cátedra que está en Papeles varios sobre la Universidad y colegios de Alcalá, I, AHN, Universidades, Libro 1222, folio 60 indicando «que está vaca». Antes del curso 1524-1525 en que está su oposición de cátedra ya aparece como catedrático de Teología en el curso anterior y deja de aparecer en Artes durante el curso 1519-1520. Por lo que es probable que se mantuviera los cuatro años como regente de Artes todos los cursos como establece la C. 25 y el curso 1522-1523, no ser regente sino, como hemos visto, leer los exámenes pertinentes al grado de maestro sin ejercer la docencia. Fue llamado a testificar en el proceso inquisitorial de Juan de Vergara y posteriormente en los de Juan de Valdés y Mateo Pascual.

34 En concreto durante el curso 1532-1533, en 1534-1535 (realizando la segunda visita de Antonio de la Fuente) y en el curso 1535-1536.

35 Gómez de Castro (1984: 542) indica «De ingenio perspicaz y de ponderado juicio. Estuvo al frente de la escuela teológica durante veinte años, y adquirió tal prestigio que en breve se hizo célebre su nombre por toda España».

36 Hay un Alonso Martínez que entró capellán en San Ildefonso en 1533. Libro de recepciones de colegiales y capellanes, AHN, Libro 1233, folio 17. ahora el primero de las Sentencias y que suele haber más de C oyentes», el maestro Barrio dijo que «lee muy bien» y los maestros Pérez y Aguila dijeron «omnia In Laudem».

En el curso 1534-1535 Fr. Pedro de Peralta -rector del colegio de San Bernardo- «dijo que están contento y que lee el quarto» (IV libro de los comentarios de las Sentencias de Gabriel Biel) Alfonso Jiménez dijo «del dr. Medina no hay más qué decir», fray Luis de Sotomayor OFM dijo del Dr. Medina que sería necesario que tuviera otro lector por las tardes "por la necesidad que tiene Medina de descansar». En el curso 1535-1536 Juan de Medina, en su condición de canónigo de San Justo, es elegido para realizar la visita ordinaria, por lo que está inmerso en la misma cuatro meses en dicho curso. En este curso se erigen, como veremos más adelante, las cátedras menores para alivio de los regentes

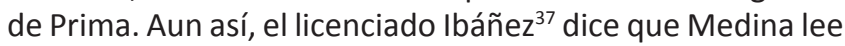
el 4. de Gabrieles, fray Martín OFM, dijo «que de Medina no hay que decir» y el maestro Alcocer ${ }^{38}$ «dijo que falta algunos días que no lee». En el curso 1536-1537, tiene ya 200 oyentes, y fray Nicolás Tolentino «dijo del Dr Medina que algunas vezes no lee las horas enteras" pero que por todo están contentos y Jorge de Olid «dijo que oye a todos salvo a Angulo y que de Medina están todos contentos». En el curso 1539-1540 fray Francisco de Ajofrín OFM dijo «que no hay que decir del syno que lee muy bien», fray Luis de Valencia OFM también indicó que estaba muy contento. El bachiller Calvo dijo "que falta algunas veces por estar malo», fray Diego Castellanos OFM dijo que "falta muchas veces» pero que están contentos. Algo que también indicó fray Gabriel de los Santos, franciscano.

Finalmente, los testimonios sobre Medina pasan al curso 1543-1544 en el cual seguían repitiéndose las ausencias por enfermedad, seguramente más frecuentes, pues fallece en 1546. Así, fray Antonio de Burgos, OFM, «dijo del dr. Medina tiene más de doscientos oyentes y que no hay más que decir del, sino que deja alguna leción por enfermedad" y fray Martín Azuasi, OSB «dijo que oye a Medina y que no hay que decir, sino que continúe». Sin embargo, son ellos los que captan el cansancio del regente cuando añaden que sería bueno que otro le sustituyese por las tardes o en las indicadas faltas por enfermedad. Este alivio se materializó en cierta forma en el curso 1536-1537 cuando se aligera el peso de la docencia de los regentes al ser las cátedras de Prima teológicas de una sola hora y no dos, como hasta ahora. Los visitadores ordinarios apenas multaron a Medina por sus ausencias. El visitador ordinario en 1527-1528 y compañero de Medina en el coro de la colegiata de San Justo, Bernardino Alonso, le indicó que "procurase no faltar» y que le sustituyera Nicolás Moratel en caso de necesitarlo.

\section{Cátedra de Santo Tomás}

Fundada asimismo por el cardenal Cisneros, se trata sin duda de la cátedra con más irregularidades que tuvo Alcalá hasta la llegada de Melchor Cano en los albores de Trento. El primer regente del presente estudio es el doctor Pedro

37 Hay un maestro Ibáñez que entró colegial del Mayor en 1538. Libro de recepciones de colegiales y capellanes, AHN, Libro 1233, folio 19.

38 Puede ser Blas de Alcocer, que entró como Ibáñez en 1538. Ver Ib. 
Ciruelo, ${ }^{39}$ que estuvo al frente de la cátedra tomista entre 1515-1516 y 1523-1524. Aunque dejase la docencia de forma oficial en 1524, seguiría como doctor del claustro de la facultad presidiendo actos de la misma. De su paso por las aulas apenas quedan testimonios en que declaran las ausencias en las lecturas de esta cátedra. ${ }^{40}$

Miguel Carrasco, ${ }^{41}$ colegial de Alcalá desde sus inicios, fue mano derecha de Pedro de Lerma, abad de la colegiata, en la Facultad de Teología, a quien sustituye como decano de la misma en 1535. Tal es la estima que se había generado hacia él que ya en 1532 el visitador teólogo de Nominales Juan de Medina apercibe a los colegiales del Mayor de San Ildefonso que no funden ni erijan nuevos colegios sin haber consultado antes a Miguel Carrasco. ${ }^{42}$ Aún en 1541 aparecerá su firma con mano trémula en una prebenda de la colegiata. Fallece poco después. En la cátedra de Santo Tomás es el sucesor de Pedro Ciruelo. Sería entre los cursos 15241525 al 1527-1528. Venía de la cátedra de Escoto, en la que estuvo entre 1520 a 1524 y antes, a su vez, en la Nominales desde 1513-1514 a 1519-1520. ${ }^{43}$ Miguel Carrasco fue confesor, amigo y testamentario del arzobispo Alonso de Fonseca, lo que le tuvo ausente de la universidad, dejando la cátedra tomista desatendida, falta principal de la cual hacen constante referencia los testigos de las visitas, especialmente

39 Entró directamente a la enseñanza complutense por mediación de Cisneros. Durante su estancia en Alcalá fue canónigo de la colegiata de San Justo. En 1524 deja la docencia en Alcalá y aparece posteriormente en el capítulo de la Junta de Valladolid para analizar los escritos de Erasmo en 1527 no siendo especialmente simpático con el holandés. A esa junta asistieron los doctores teólogos de la facultad: Sancho Carranza de Miranda - beneficiado de San Justo-, Miguel Carrasco -regente-, Pedro Ciruelo -regente-, Alonso Enríquez, Pedro de Lerma -deán-, Fernando Matatigui -regente-, Juan de Medina -regentey Antonio Rodríguez de la Fuente. Todos los hombres fuertes de la Facultad de Teología son citados y todos, salvo el conocido Ciruelo, se mostraron favorables a Erasmo. Cfr. Beltrán de Heredia 1972: 9-120, con la edición de las actas. También en Bataillon 1950: 243-270. Existe también un pequeño estudio sobre la Junta de Valladolid de 1527 en Paz y Meliá y Serrano Sanz 1902. Pedro Ciruelo pasó en 1533 a canónigo magistral de la catedral de Segovia y desde 1536 hasta su muerte, en la de Salamanca. Ciruelo admitía que la Teología de Santo Tomás era dificultosa para «los españoles que tienen siempre prisa por aprender», en Gómez de Castro 1984: 542. En 1530-1531 es citado en el curso como doctor, pero no preside ningún acto. Desde el curso 1531-1532 inclusive ya no aparece en ningún acto.

40 Una de las denuncias a los procesos inquisitoriales de Ignacio de Loyola en Alcalá fue realizada por el Dr. Pedro Ciruelo en 1526. Véase Dalmases 1977.

${ }^{41}$ Entró colegial del Mayor de San Ildefonso en agosto de 1508. Fue rector en $1510-1511$ y 1516-1517 y parte del curso siguiente a petición de Cisneros antes de su muerte. Desde 1522 aparece citado como doctor de la Facultad de Teología y, presumiblemente, desde que fue catedrático, aunque no se conserven las actas antes de dicha fecha. Una vez muerto Fonseca, Miguel Carrasco estuvo trabajando en las constituciones del colegio de Santiago de Salamanca, que fueron presentadas por el conde Monterrey, Luis Cabeza de Vaca y Carrasco, en 1539, véase Sendín Calabuig 1977.

42 Visitas de aulas, AHN, Universidades, Legajo 65, n.ㅇ 48, folio 142. Sin duda el nuevo colegio Trilingüe traía de cabeza a los visitadores por los gastos en las nuevas prebendas colegiales que dependían de las rentas del Mayor de San Ildefonso. Diego de la Puente, canónigo de San Justo, doctor teólogo de Alcalá y visitador del curso 1529-1530 decide suspender las nuevas prebendas del Trilingüe y derivar dichos ingresos a la finalización del colegio-hospital de San Lucas, empresa que sí plasmó en las constituciones el cardenal Cisneros y aún quedaba por ejecutar.

${ }_{43}$ Como hemos indicado ut supra, las regencias antes de la reforma de 1517 eran de 8 años. en el curso $1527-1528 .{ }^{44}$ Es precisamente el periodo de su protector, Fonseca, arzobispo de Toledo entre 1523-1534, el de más inestabilidad de las cátedras tomista y escotista en Alcalá. Alvar Gómez describe la injerencia del arzobispo en dos visitadores ordinarios ${ }^{45} y$, por tanto, interviniendo tanto en la elección de dichos visitadores como en su posterior visita, realizada a interés del arzobispo y cuyo fin era elegir a un rector que Fonseca pudiera manejar a su antojo. ${ }^{46} \mathrm{El}$ sustituto en las ausencias de Miguel Carrasco fue el colegial Jorge de Naveros, ${ }^{47}$ aunque no pudo atenderla mucho cuando a su vez era regente de Artes. También le sustituyó en 1527 el colegial Juan Gil/Egidio, ${ }^{48}$ precisamente durante la Junta de Valladolid. Respecto a las visitas de cátedra que tuvo Miguel Carrasco, hay que destacar las quejas de los estudiantes por sus ausencias. Ya en su primer curso en Santo Tomás, el de 1524-1525, fray Gonzalo Patoxa dijo "que hay ausencias», fray Fernando dijo que "hay ausencias en esta Cátedra» y el maestro Juan también protesta por las faltas. En el curso de la Junta de Valladolid, el de 1527-1528, Francisco Martínez, bachiller se quejó de la poca atención de esta cátedra ya que estuvo "cinco o seis meses o más» sin nadie que leyese el curso anterior. Y del curso presente "solo han leído dos artículos de la secunda secundae», García Arias se queja de lo mismo y por eso ni siquiera va a las lecciones si es que las hay, porque "no ha habido continuación», fray Francisco de Jerez se quejó de que en un año "se ha leído solo un mes» y fray Juan de Quinconces dijo algo muy significativo contra las visitas de cátedras: "que para que se hacía esta visitación pues que no se abia de remediar» y más adelante, indicó directamente que la cátedra «no tiene regente». Fray Agustín de Aragón dijo que «esta(ria) contento del lector de Santo Tomás sino hiciese faltas que de San Lucas acá no ha leydo sino tres o cuatro lecciones e que el año pasado hizo muchas faltas», fray Francisco de Campo dijo que "estaría contento si fuera más continuo ya que sólo ha leydo tres o cuatro veces», y el maestro Pedro Losado, colegial del Mayor, dice que Carrasco, las pocas veces que ha ido "ha leido proposiciones de Herasmo más que de Santo Tomas y que si continuase estaría contento del». Bernardino Alonso, visitador del curso $1527-1528$, se quejó de sus ausencias

44 Ejemplo de ausencias también fue su designación como miembro en el tribunal que investigaría a Ignacio de Loyola y los ensayalados en 1526-1527 en Alcalá emitiendo un informe favorable a estos junto a Juan de Figueroa, vicario arzobispal, así como la asistencia a la Junta de Valladolid de 1527 para discutir las proposiciones de Erasmo.

45 Gómez de Castro (1984: 564-566) en la visita de Bernardino Alonso de 1527-1528 cotejada con la manipulación del visitador en AHN, Universidades, Legajo 555-1, texto en García Oro y Portela Silva 2006: 180-188; y en las visitas de Diego de Albornoz en 1530-1531 y Hernán Vázquez en 1531-1532 en Libro de cuentas de frutos de rentas y gastos (1524-1530), AHN, Universidades, Libro 747F, texto en García Oro y Portela Silva 2006: 302-340.

46 La visita de Bernardino Alonso en 1527-1528 fue tan controvertida que requirió la visita extraordinaria en 1528 del obispo auxiliar Pedro del Campo, antiguo colegial complutense, siguiendo las indicaciones de la constitución 63, en que se puede recurrir al cabildo de la sede primada de Toledo en caso de que pueda haber daño o menoscabo a la universidad. Visitas ordinarias, AHN, Universidades, Legajo 555, Expediente 1.

47 Libro de memoria del pago de tesoreros, AHN, Universidades, Libro 814, folios $139 v$ y $147 r$. Hasta su regencia en Biblia fue canónigo de Palencia y estudiante de griego en Lovaina. Fue predicador real.

48 Libro de cuentas del tesorero 1526-1528, AHN, Universidades, Libro 652, folio 46r. Es interesante el dato, ya que la designación corría a cargo del titular, Miguel Carrasco, secretario de Alonso de Fonseca. 
cuando describía - eso sí de forma etérea - en el acta de su visita que "halló algunas cosas defectuosas (en las visitas de cátedra) que él mandó a algunos regentes de palabra que remediasen en sus liciones e otras que dexó memoria». ${ }^{49}$

Siendo Jorge de Naveros el sustituto de Miguel Carrasco, hubiera sido el camino normal que accediera aquel a la cátedra tomista en el curso $1528-1529 .{ }^{50}$ Y presentó su candidatura, pero fue impugnada por Nicolás Moratel que también opositaba, ${ }^{51}$ apelando a las constituciones. Moratel alegó que Naveros no podía acceder a Santo Tomás pues esto conllevaría dejar su cátedra filosófica, ya que en dicho curso estaba explicando la Física del tercer año. Además, Moratel también estaba rondando opositar a una cátedra pues había sido sustituto de Juan de Medina el curso anterior. Así, tras el pleito, Nicolás de Moratel accedió a la regencia de Santo Tomás en los cursos $1529-1530$ y $1530-1531 .^{52}$ Aunque no completó su cuatrienio, pues desde el curso 1531-1532 ya no aparece citado como doctor de la facultad sacra. No quedan registros de testigos en las visitas de cátedra sobre su docencia ni referencia en las actas de las visitas ordinarias.

Juan Gil o Egidio sustituye a Moratel en la regencia de Santo Tomás desde abril de $1531^{53}$ hasta diciembre de ese

49 La visita de Bernardino Alonso en García Oro y Portela Silva 2006: $180-210$

50 Beltrán de Heredia (1973: 129) indica erróneamente la ausencia de la cátedra de Santo Tomás en este curso por la peste, pero lo cierto es que se opuso Jorge de Naveros como indicamos en el texto. El dominico se basa en la visita de Bernardino Alonso, aunque hay que tener en cuenta que hasta 1540 apenas hubo regentes que no hubieran pasado antes por las aulas complutenses. Tudela y Cano son los primeros.

51 Papeles varios sobre la Universidad y colegios de Alcalá, I, AHN, Universidades, Libro 1222, folios 47-53. En el Libro de recepciones de colegiales y capellanes, AHN, Universidades, Libro 1233, folio 11 , se indica que Moratel entró colegial del Mayor en 1521. Hay confusión con otro Nicolás Moratel que entró colegial en 1591. Reza después en el manuscrito que fue abad de la Universidad de Lérida, pero no podemos contrastarlo ya que hasta el momento no hemos encontrado a ningún Moratel entre la jerarquía del estudio ilerdense.

52 Moratel regentó los cuatro años completos de la facultad de Artes entre los cursos 1524-1525 (Súmulas) y 1527-1528 (Metafísica). Paralelamente a su regencia de Artes obtiene el título de licenciado en Teología según consta en Libro de actos de la Facultad de Teología, AHN, Universidades, Libro 396F, folio 21. Durante la visita de Bernardino Alonso, en 1527-1528, fue suspendido de voto, ver AHN, Legajo 555, 1. Texto editado en García Oro y Portela Silva 2006: 204. Luttikhuizen (2017: 188) dice que Juan Egidio sustituyó en 1531 al lector de teología anterior -Moratel- por su muerte. Lo cierto es que en agosto de 1535 aún el visitador Juan de Medina, respecto a una deuda contraída por Moratel, dice de él en el acta «no estar a mano ni residente en un lugar». Por tanto, desapareció de Alcalá hacia 1531 sin que sepamos la fecha exacta de su muerte.

53 Habría estudiado Artes hacia 1520. Entró colegial en 1525 junto a Pedro Alexandre, amigo y compañero. Egidio enseñó Matemáticas en 1526 y fue regente de Artes entre 1528-1529 y 1530-1531, Libro de cuentas del tesorero 1526-1528, AHN, Universidades, Libro 652, folio 32 r. Sobre la sustitución en la cátedra de Santo Tomás ver Papeles varios sobre la Universidad y colegios de Alcalá, I, AHN, Universidades, Libro 1222, s/n. En 1532 pasó a enseñar Teología en Sigüenza de forma interina según González Montano 1567, y después pasó a la canonjía magistral hispalense, la más importante del coro catedralicio de Sevilla. La ocupaban aquellos predicadores con más valía en las catedrales de Castilla. Por la de Sevilla pasarían además Sancho Carranza de Miranda, Pedro Alexandre, Constantino de la Fuente y Pedro Zumel, todos estudiantes complutenses, en el XVı. Véase Hazañas y La Rua 1890: 165-175, y González Montano 2010: 283. Su expediente inquisitorial de Sevilla en Proceso de fe de Juan Gil Egido, AHN, Inquisición, 2055, Expediente 11/3. De su figura, véase Boeglin 2005. año, tras opositar frente a Diego Naveros y Alonso Prado. ${ }^{54}$ Por tanto, no duró ni un curso entero, aunque en ese tiempo unió la regencia de la cátedra principal a la rectoría. Obtuvo el doctorado teológico el 3 de diciembre de 1530, estando presentes Bernardino Ximénez de Cisneros (hermano del fundador) y Alonso de Manrique, arzobispo de Sevilla (15231538), amigo de Alonso de Fonseca y arzobispo de Toledo, 55 lo que demuestra la importancia que había despertado este teólogo entre la jerarquía eclesiástica. De las visitas conservadas queda constancia que fue estimado por sus oyentes de Teología como indican en el curso 1531-1532 el frater Diego de Góngora dijo que estaba contento y el frater Alfonso de Robledillo dijo «que lee a S Thomas y le parece muy bien siempre». Después de Alcalá se trasladó a Sigüenza para enseñar de forma interina en la cátedra de Teología antes de la llegada de Pedro Guerrero. En Sevilla, además de su conocida canonjía magistral, enseñó Teología en el colegio-universidad y redactó unas constituciones a petición de su rector. ${ }^{56}$

A Egidio le sustituye Pedro Alexandre/Alejandro ${ }^{57}$ cuando se provisiona la cátedra de Santo Tomás el 9 de marzo de 1532 tomándola este colegial, que ostentaba el cargo de rector en dicho curso y amigo personal de Egidio. No se conservan actas de visitas a sus aulas. Alexandre fue canónigo magistral de Sevilla a comienzos de 1533, Ilamado por el cardenal arzobispo Alonso de Manrique. Es la fecha en la que dejó Alcalá y se trasladó para tomar la canonjía de forma vitalicia. Allí apenas se conservan documentos de su estancia y su carrera se malogra con su muerte prematura en el verano de 1534. Alexandre fue elegido rector en 15311532 según explica Gómez de Castro, ${ }^{58}$ por intervención de Alonso de Fonseca. En el curso 1531-1532 hubo graves enfrentamientos entre los partidarios de Pedro Alexandre y de Juan de Angulo. Ambos y sus discípulos frenaban el progreso de los estudiantes poniendo coto al acceso a las licencias y doctorados teológicos. La situación fue tan grave que se tuvo que nombrar a dos árbitros: Juan de Medina y Francisco de Vargas. Declararon que Pedro Alexandre tenía preferencia por ser doctor teólogo más antiguo, pero Juan de Angulo tendría preferencia para acceder a una canonjía de San Justo, por la antigüedad como colegial del Mayor. ${ }^{59}$ Probablemente fuera esta la causa principal por la que

\footnotetext{
54 Oposición en AHN, Universidades, Legajo 755, s/f.

55 Ver Libro de actos y grados, AHN, Universidades, Libro 397F, folio $42 r$.

56 Hazañas y La Rúa 1890: 380-387.

57 Entró colegial en 1525, de la diócesis de Córdoba. En el importante trabajo de Luttikhuizen 2017: 188 hay un error, pues indica que el rector complutense es en realidad Petrus Alexander, carmelita, doctor en Teología por París en 1534 y posterior luterano. Amigo de Encinas, este Pedro Alexandre francés fue hecho preso por conclusiones heréticas, pero se escapó. Fue profesor en la Universidad de Heidelberg, canónigo de Canterbury en 1548, pastor en Estrasburgo en 1555 y en la iglesia francesa de Londres en 1560. Es posible que Luttikhuizen siga el estudio de León de la Vega (2011: 596), que también confunde los dos Alexander citando a Encinas (1992: 387). Sobre el Pedro Alexander francés véase la biografía Denis 1977: 551-560. El Pedro Alexandre español, rector de Alcalá, amigo de Egidio, que pasó a la canonjía magistral hispalense, murió en Sevilla en 1534 y, por tanto, tuvo difícil enseñar en Estrasburgo en 1555. Las actas del cabildo catedral en que se da la noticia en Hazañas y La Rúa 1890: 370.

58 Gómez de Castro 1984: 566

59 Certificaciones de estudios, listas de licenciados...AHN,
} Universidades, Legajo 754. Sin foliar. 
Pedro Alejandro se fue hacia Sevilla. Gómez de Castro indicó que el arzobispo de Toledo manejaba la elección de las cátedras complutenses a su antojo, por medio de la mujer de su mayordomo Francisco Maldonado, Ana de Ulloa. ${ }^{60} \mathrm{~A}$ los dos meses de la rectoría de Pedro Alexandre - quizá influenciado por Juan Egidio al que todos Ilamaban «el biblista»se erige la cátedra de Sagrada Escritura en la Universidad de Alcalá, como veremos más adelante.

Tras la marcha de Alexandre a la sede hispalense se incorpora de forma interina fray Domingo de Santa Cruz ${ }^{61}$ $\mathrm{OP}$, al que hasta ahora le conocíamos por su nombre laico, Pedro Hernández de Saavedra. De su paso por las cátedras de Alcalá nos quedan dos testimonios. El primero, y más sólido, el de su regencia frente a la cátedra menor de Santo Tomás, que toma como primer regente tras el desdoblamiento de las cátedras en 1536 . El segundo, son las citas que pueden probar su paso por la cátedra principal tomista como apoyo en los años convulsos en que estuvo tan desatendida, la cual se vaca en $1528-1529^{62}$ pero no se opuso nadie. Es en el curso de 1531-1532 cuando se cita en las visitas de cátedras a un "fraile que lee a Santo Thomas". Descartado fray Andrés de Tudela, que no entraría hasta 1540, nos queda como mejor opción que fray Domingo de Santa Cruz tuviera sus meses de regencia previa como sustituto hasta que se vacase la principal y él obtuviera después la cátedra menor tomista.

Jerónimo Velasco entra de forma oficial al ser proveída su cátedra a finales de octubre de 1534, disputada contra Alfonso Prado, al que muchos creían que realmente le correspondía la cátedra por experiencia. ${ }^{63}$ Velasco fue regente de Santo Tomás ente 1534-1535 y 1537-1538. En las visitas de cátedra leía la lección muy de mañana, quizá coincidiendo con la misa que se celebraba y a la que no asistía nadie. Al ser obligatorio que no coincidiera con ninguna clase, el curso siguiente Jerónimo Velasco leía después del mediodía, aunque a los alumnos les sabía a poco y demandaban dos horas. De las visitas a sus clases en este periodo sabemos que en 1534-1535 tuvo 60 oyentes entre los cuáles citaron como testigos Alfonso Jiménez que dijo «el dr. Velasco lo que ha leído ha sido muy bien y que suele sacar a la hora mucho fruto y que lee dos lecciones enteras y suele

60 Gómez de Castro 1984: 571. El humanista cita a una «mulierculae» Ana o Juana de Ulloa, mujer de Francisco Maldonado, mayordomo de Fonseca, como la electora a capricho de los regentes de cátedra y que al parecer iba alborotando la universidad como mano oculta del arzobispo. Maldonado - y su mujer - aparece en el testamento de Fonseca heredando la nada despreciable suma de 250.000 mrs. Texto en Sendín Calabuig 1977: 243.

61 Entró colegial del Mayor en 1519. Se licenció en Teología en diciembre de 1524 y doctor en enero de 1525, precisamente el curso en el que sería rector de Alcalá. Profesó en el convento de Santa Cruz de Segovia el 11/XI/1526 siendo compañero de Domingo de Soto en París, en el colegio de Monteagudo, véase García Villoslada 1938: 390.

62 Papeles varios sobre la Universidad y colegios de Alcalá, I, AHN, Universidades, Libro 1222, folio 270.

63 Gómez de Castro (1984: 543). Accedió al doctorado en noviembre de 1534. Acababa de finalizar el curso completo de Artes cuya regencia en Súmulas comenzó en 1529-1530. Aplica, por tanto, experiencia en docencia en la enseñanza de Santo Tomás en la que permanece hasta 1539-1540, curso que ya imparte el dominico fray Andrés de Tudela. Discípulo de Alonso de Prado en Filosofía, Gómez de Castro le describe como "varón esclarecido en criterio y doctrina». Llegó a ser obispo de Oviedo. Participó en Trento como teólogo. tener hasta LX oyentes», fray Luis de Sotomayor OFM «dijo que la de Sancto Tomás se les haze de mal la lección de la mañana porque es muy de mañana». Fr. Antonio de San Estebán OFM dijo «que debería leer la lección de Moral que se presupone a la Doctrina». En el curso 1535-1536 baja a 25 oyentes. En este curso el bachiller Juan Rodríguez «dijo que lee una lección de tarde a las tres. La secunda secundae», fray Juan Navarro OFM «dijo que faltó algo al principio en ha de leer y lo demás lo haze bien salvo que es menester que alzase mas la voz y que sería mejor que leyese dos lecciones», el maestro Simón "dijo que lee tan apresurado que algunos no le perciben y que conviene mucho que se lean dos lecciones como se leyan antes». Y en el curso 15361537 Jorge de Olid OFM dijo de Velasco que «lee la secunda secundae desde junio y que todos están contentos». El bachiller Juan Rodríguez «dijo que lee una lección de tarde a las tres. La secunda secundae». ${ }^{64}$

Le sigue fray Andrés de Tudela OP, que obtiene la titularidad de Santo Tomás en octubre de 1539. Permanece solo un curso en Alcalá y le cita Martín Garcetas «que está contento». A Tudela le sustituye Pedro de Castro, ${ }^{65}$ ya que se proveyó la regencia principal de Santo Tomás a Pedro de Castro a comienzos de octubre de 1540. Estuvo solo dos cursos, pues le sustituye Melchor Cano a mediados del curso 1542-1543. No se conservan testimonios de sus oyentes. Por último, fray Melchor Cano OP, ${ }^{66}$ que accedió a la regencia de Santo Tomás en marzo de 1543 «al Padre Doctor Fray Melchor Cano de la orden de Santo Domingo». No aparece en el claustro de doctores del libro de actos de Teología, aunque sí en los "sermones latini doctorales». ${ }^{67}$ Se conserva su manuscrito de Anotaciones a la Secunda Secundae de Santo Tomás que realizase en Alcalá68 y las respuestas de los oyentes de sus aulas, que al parecer no están muy de acuerdo con sus lecturas en los tres cursos que estuvo en Alcalá. ${ }^{69}$ Así, fray Diego de la Riba, OFM, dijo «que el padre Cano lee la 2. $2^{\mathrm{e}}$ q. De Restitutione. Suele haber hasta $\mathrm{C}$ oyentes dijo que lee bien pero que estos escriptos no le parecen bien que no encomiendan a la memoria y que son continuos en sus lecciones y lee las horas enteras», Francisco del Olmo

64 Segunda parte, 2a sección de la Suma Teológica de Santo Tomás. En concreto sobre las virtudes teologales y las cardinales, carismas y estados.

65 Hijo del conde de Lemos, recibió el grado de doctor en diciembre de 1536. Fue filósofo y matemático. Fue obispo de Salamanca (15451553) y de Cuenca (1553-1561).

66 Sobre el paso de Melchor Cano por Alcalá no suele haber diferentes puntos de vista y todos ellos con poca crítica. Abellán García (1976: 109) indica de él una "obsesión patológica» con todo aquello que se alejase de su doctrina y no fuera cercano a la "pietatis», mostrable aquí con la cita de los estudiantes en la visita de su cátedra. No obstante, es interesante la monografía con tintes hagiográficos y panegíricos de Hernández Martín 2010.

67 Libro de actos de la Facultad de Teología, AHN, Universidades, Libro $396 \mathrm{~F}$, folio $78 \mathrm{v}$. Son las únicas referencias que aparecen de fray Melchor.

68 Nicolás Antonio ya cita un manuscrito en la Biblioteca Vaticana. Caballero (1871) cita además otro en San Esteban de Salamanca. Y el investigador de la figura teológica del dominico, Juan Belda Plans, con numerosas monografías, cita otro en Sant Cugat del Vallés, aunque sin citar a Fermín Caballero y tratando el tema de inédito. Llama la atención que los dominicos no hayan analizado nada en todo el siglo xx de estos documentos de Alcalá de su fray Melchor. Belda Plans 1982: 59-103r, con abundante bibliografía.

69 AHN, Universidades, Legajo 65, sin foliar. 
«dijo que hay que decir que sería bien que el padre Cano declamase más la letra de $\mathrm{S}$. Thomas y que estos escriptos no le parecen bien», el licenciado Villalpando «dijo que de Cano está contento», fray Juan Belón OSF «dijo que Cano que lo hace muy bien salvo que Cano tiene una costumbre que algunas proposiciones aunque no están condenadas dice que son hereticas» Respecto a esta última denuncia, no en vano, en carta al regente de Santo Tomás fray Mancio del Corpus Christi OP en 1548, le indica que sus enemigos están enviado a Roma quejas sobre su doctrina y su forma de actuar. $^{70}$ Tenía fray Melchor cerca de cien oyentes. Permanece tres cursos en Alcalá hasta 1546 que obtiene la titular en Salamanca._El siguiente regente fue fray Mancio del Corpus Christi OP que permanece de 1548 a 1564, estableciendo, por primera vez, una continuidad en esta cátedra $^{71}$ aunque fuera ya de nuestro estudio. No queda constancia de que Cano recibiera alguna multa, al menos así lo hemos constatado con las fuentes indicadas.

\section{Cátedra de Escoto}

Escoto no fue una cátedra provechosa hasta 1540 a pesar de ser la tercera cátedra fundacional de Cisneros. Regentada por catedráticos ingrávidos desde sus mismos inicios, no pasaba de ser un mero trámite para los estudiantes franciscanos en su camino hacia el bachillerato o la licencia teológica, como veremos a continuación.

Miguel Carrasco inicia nuestro estudio, ya que ocupa la cátedra desde 1521/1522 hasta $1524-1525^{72}$ sustituyendo a fray Clemente OFM, fallecido en $1521 .^{73}$ No hay constancia de testigos de sus aulas al no conservarse actas antes de 1523. Le sustituyó Fernando de Burgos conocido por Matatigui. ${ }^{74}$ Ingresó colegial en 1516 proveniente de la diócesis de Burgos. ${ }^{75}$ Es citado para asistir a la Junta de Valladolid de $1527 .{ }^{76}$ Los oyentes en los cursos en los que regentó Escoto, entre 1524-1525 y 1527-1528, se quejaron, año tras año, de su incapacidad docente sin que nadie hiciera nada, y por ello asistían a sus clases la mísera cifra de 8 estudiantes. Es muy probable que solo los franciscanos del colegio menor de San Pedro y San Pablo. ${ }^{77}$ En el curso 15251526, fray Martín de Zúñiga, por ejemplo, dijo que «no está contento de su leer porque paresce que no debe proveer bien sus lecciones», fray Antonio de los Ángeles dijo que «le paresce que podria leer más letra de lo que lee y lo que lee no lo declara bien», el maestro Requena dijo que "su

\footnotetext{
70 Copia de esta carta en Caballero 1871: 467.

71 Sobre su figura, véase Beltrán de Heredia 1972, Vol. II: 364-400.

72 Libro de cuentas de frutos, rentas y gastos 1509-1513, AHN, Universidades, Libro 744 f. 101 y Libro de cuentas de la visita de Pedro González de Medina 1522-1523; AHN, Universidades, Libro 814, folio124.

${ }_{73}$ Hasta su muerte aparece en el Libro de actos de la Facultad de Teología, AHN, Universidades, L. 396F. Consta el pago de su enterramiento y lápida en San Justo de Alcalá en 1520. Ib. folio 32.

74 Datos anteriores a 1520 en AGS, Patronato Real, Legajo 542.

75 Desde 1520 aparece citado en el claustro de doctores de la Facultad de Teología. Matatigui se doctoró con anterioridad a 1520 ya que aparece presidiendo desde entonces, Libro de actos de la Facultad de Teología, AHN, Universidades, Libro 396F, folio 2.

76 Bataillon 1950: 247-258; Beltrán de Heredia 1974: 89 y ss. Las proposiciones contra los supuestos errores de Erasmo en Ibíd.: 17-23.

77 Sobre este colegio-convento, fundado por Cisneros en 1510 para 13 estudiantes franciscanos y dos fámulos, véase la constitución 34 .
}

doctrina es muy escabrosa», el futuro regente Martín Malo dijo que «trabaja en su lectura e que estaría más contento con otro regente pero que no haze faltas en sus oras. Si bien es cierto que había algunos oyentes que estaban contentos con él, su falta de auditorio - no pasaban de 20- provocó que en dicho curso el rector y consiliarios le exigieran a Matatigui que fuera más continuo «e provea bien e con diligencia e procure acabar el curso y que tenga de sustituto a Juan Bivas».

Por tanto, en los cuatro cursos en que regentó la de Escoto, Matatigui demostró que no estaba capacitado para la docencia. Era un teólogo con una capacidad mediana para el razonamiento, pero casi nula para la enseñanza con un auditorio paupérrimo.

A Fernando de Burgos le sustituye Francisco de Vargas. ${ }^{78}$ Conocido es el triunvirato ${ }^{79}$ de Vargas, Juan Gil y Constantino Ponce como herejes de Sevilla, que pasaron por las aulas de Alcalá. Francisco de Vargas explicó moral en Alcalá y pasó a Sevilla al colegio de Santa María de Jesús como Egidio y Alexandre. Erasmista, fue maestro del príncipe Felipe en 1543 y capellán real. ${ }^{80} \mathrm{Al}$ igual que Matatigui, no tenía grandes habilidades para la docencia, pero creemos que al ser uno de los miembros más antiguos de la facultad, pudo permanecer en el puesto sin mejorar curso a curso y sin ser multado. Estuvo entre 1528-1529 y 1532-1533 como regente y de las visitas de sus aulas tenemos ejemplos claros de su pobre enseñanza. Asistían a su clase 20 estudiantes. Así, para el curso 1531-1532, ${ }^{81}$ el maestro Gabriel Manrique dijo que no está contento de Vargas «porque no se explica», el frater Diego de Góngora dijo de Vargas que falta muchos días y que no se explica, el frater Alfonso de Robledillo dijo «que viene muy tarde a leer y suele terminar temprano" y que no tiene "habilidad explicativa». Para el curso 1532-1533 el bachiller Villareal dijo «que suele haber hasta XX oyentes lee ahora el 3. De Charitate. Dijo que no se explica bien por falta de su lengua, fray Antonio dijo «que falta algunas lecciones e no tiene buena lengua».

En junio de 1533 accede a la regencia de Escoto Diego de Naveros ${ }^{82}$ sustituyendo a Vargas y permanecerá el cuatrienio completo, hasta 1537. Hasta el curso 1532-1533 no aparece en el claustro de doctores de Teología. Siendo regente de

78 Hay otro Francisco de Vargas que entró colegial en 1532. Ver Libro de actos y grados, AHN, Universidades, Libro 397F, folio 50 . El nuestro fue regente de Artes comenzando las Súmulas en el curso 15171518. Fue canónigo de San Justo y realizó la segunda visita ordinaria del cuso 1528-1529.

79 Expresión acuñada por primera vez por Bataillon 1950: 524. Libro de actos de la Facultad de Teología, AHN, Universidades, Libro 396F, folios 6-10. Desde el curso 1526-1527 aparece citado como doctor de la facultad. En diciembre de 1532 es el regente de la cátedra de Filosofía Moral sucediendo a Alonso de Prado.

80 Maravall 1972: 53-92.

81 Francisco de Vargas aún no había «desaparecido de Alcalá» como le cita para el curso 1532-1533 Beltrán de Heredia 1974, Vol. IV: 120.

82 Existen dos Naveros. Diego/Santiago/Jacobo que entró colegial en 1521 y Jorge que accede a San Ildefonso en 1524. Este último sin embargo se doctora antes al no compaginar, como Diego, los estudios con la docencia. Diego entró colegial en 1521 proveniente de la diócesis de Palencia. En febrero de 1523 aparece examinándose del segundo principio junto a Domingo de Soto y Nicolás de Moratel. No se indica quien preside Libro de actos de la Facultad de Teología, AHN, Universidades, Libro 396F, folio 10 . Hasta noviembre de 1530 no es nombrado licenciado en Teología doctorándose apenas un mes más tarde. 
Artes fue aficionado al juego de naipes, descubierto en varios cursos y penalizado en enero de $1530 .^{83}$ Lo cierto es que poco después hubo opositado sin éxito a la de Santo Tomás en 1531 y 1532, ganando como vimos ut supra Juan Gil primero y, en su ausencia, Pedro Alexandre. Cuando llega la novedad de este conocido colegial a Escoto (entró en San Ildefonso en diciembre de 1521) supuso un auditorio de 90 estudiantes. En el curso siguiente bajaron a 30 . Es probable que, al no alcanzar la cátedra tomista, le causase desazón, pues llegó expresar que Escoto era mentira. Los estudiantes muestran su desesperación ante semejante desahogo. Uno de los más interesantes es el testimonio de fray Luis de Sotomayor, OFM, en el curso 1535-1536 que demanda que le multen cuanto antes como hacen en otra universidad: «dijo que lee el primero de la distinción octava e no más de una lección. Que hasta aquí muchas faltas ha hecho en entrar tarde como en faltar muchas lecciones y que no estudia y él se jacta dello. Y que se ocupa en otras cosas en hazer súmulas y a esta causa no declara. $Y$ que ha dicho que esta cathedra (la) tiene de per accidens porque lo otro le da de comer. Que ha que comenzó el primero casi un año e ha pasado poco porque ha faltado muchas lecciones y que es menester que le multen bien como se haze en Salamanca». Fray Francisco de Montoya OFM «dijo que en su conciencia que la cáthedra de Scoto está totalmente perdida por las siguientes causas: la una, porque diz que hace cosas de lógica en que se ocupa, e lo muestra en el leer. Segunda porque falta muchas lecciones, la tercera porque passa poco que hay día que no pasa de diez renglones y que ya ha más de un año que comenzó el primero y ahora va en la octava distinción y se van los frailes y estudiantes porque no passa», fray Pedro de Zayas, OFM. «dijo que no lo oye y que sabe que otos no lo oyen porque no lee a Escoto con aquella afficción que debía y que muchas vezes dice en algunos passos: in hoc mentitas est Scotus», fray Cipriano (de Huerga, futuro regente de Biblia en Alcalá), OCist «dijo que le oye dende antes de vacaciones y le parece que no estudia bien ni trabaja ni lee distinta e claramente. Algunas veces viene tarde y que si no se leyese a Durando sería mejor que se leyese dos lecciones porque pasase más, que pasa poco y lee poca letra».

Tras tres cursos demostrando su pobreza y demostrándolo públicamente sin pudor es multado en el curso 1535-1536:

determinaron primeramente que el doctor Naveros catedrático de Escoto que por muchas negligencias e defectos que parece haber tenido por la visitación hecha de su cátedra después que fue elegido por catedrático, e lo poco que ha pasado, que se debe penar e pague de pena once florines para el arca del Colegio, con apercibimiento que si para otra visita, que será antes de Pascua de Espíritu Santo, no se enmendare, que será privado de la dicha cátedra.

Le sucedió a finales de septiembre de 1537 Miguel del $\operatorname{Arco}^{84}$ cuando era titular de la menor de Escoto en una suerte de promoción interna. Se había doctorado en febrero de 1535. Por primera vez desde fray Clemente OFM, se renueva la regencia de Escoto. Lo hace Arco en octubre

83 AHN, Universidades, Legajo 555-1, folio 260v. Texto en García Oro y Portela Silva 2006: 290.

${ }_{84}$ No confundir con el dominico P. Miguel de Arco, provincial y confesor de Vitoria. de 1541. Es precisamente en esas fechas en que Miguel del Arco consigue levantar la cátedra que habían hundido sus predecesores. En 1540-1541 los estudiantes comienzan a decir de él que es provechoso y vuelve a recoger el interés por esta vía teológica con una audiencia de 90 estudiantes, algo inaudito en la cátedra de Escoto. Así, en las visitas de sus aulas para el curso 1539-1540 dijo fray Francisco de Ajofrín que Arco "se ha enredado" y, en la visita de verano, «que ha oydo por San Lucas dos años que se comenta el 4. y que acaba el sust.uto en la 4. a cuestión y que esta Cathedra no se haze bien ni se aprovecha nada y encarga la conciencia», fray Luis de Valencia dijo "que está perdida la cátedra», el bachiller Calvo dijo "que faltaba también algunas lecciones y ha passado poco y que muchas vezes parecía que no venía proveydo". Pero en el curso 1540-1541 con 80 oyentes, ya se había enmendado a tenor de las declaraciones de los testigos. Así, el primero, fray Francisco Verdugo OFM, dijo que Arco «lee el 1.ㅇ de Escoto en el Proemio y que lo comenzó ahora después de San Lucas y que suele tener LXXX oyentes y que lee bien y declara y está contento». Para el curso 1543-1544 con 40 oyentes fray Antonio de Burgos, OFM, «dijo que Arco lee de ocho a nueve de la mañana y lee la Dix de primero y que lee muy bien y que todos están contentos y que no hay faltas, sino que continúe».

\section{Cátedra de Sagrada Escritura}

Fue instituida en enero 1532 bajo los auspicios del rector Pedro Alexandre y creemos que con una alta posibilidad de que fraguase esta decisión el luterano Juan Egidio, gran amigo de Alexandre y conocido en Alcalá como «el biblista». Alexandre apenas llevaba dos meses el frente de la institución, pero el Diálogo de la Doctrina Cristiana de Valdés llevaba publicado desde 1529 y probablemente con fuerte influencia de Lutero $^{85}$ en el biblista Juan Egidio, que pasó a Sigüenza a primeros de 1532 quizá huyendo del Santo Oficio. No deja de sorprender que, al alimón de la creación de esta nueva cátedra teológica, ya en 1533 el visitador real enviado por Carlos I para conocer el estado de la Universidad de Alcalá, Francisco de Navarra, indicase como falta importante «vos el retor e colegiales no oys misa e oficios que la constitución dispone» ${ }^{86}$ denuncia que los visitadores ordinarios ya habían puntualizado esto en casi todos los cursos desde 1525-1526. No se asistía al oficio divino, ni al rezo de la Salve, ni a la misa matutina.

En el acta de institución de la cátedra ${ }^{87}$ consta que se pague al regente como al resto de catedráticos y se le multe "conforme a las dichas Catedras del dicho Colegio». Por tanto, quedaba adscrita a la Facultad de Teología y a los actos recogidos en las constituciones 45 y 46 .

Fray Dionisio Vázquez OSA ${ }^{88}$ es el primer titular de la cátedra de Biblia desde 1532 hasta 1536 en que está ya gravemente enfermo en Toledo. ${ }^{89}$ Moriría la primavera de 1539. En

85 Gilly 1983.

86 AGS, RGS, I-1534. Texto en García Oro y Portela Silva 1999: 108-113.

87 Registro de escrituras ante los escribanos contadores de la hacienda y rentas del Colegio Mayor de San Ildefonso y Universidad de Alcalá 1528-1536, AHN, Universidades, Libro 4F, folio 278.

88 Sobre su figura ver Morocho Gayo 2000.

89 AGS, Estado, legajo 38, folio 139. 
este período, testimonian los estudiantes que se encuentran contentos con él, pero destacan su orientación hacia la cábala aprendida de Viterbo en Italia y su interpretación de la Biblia desde la perspectiva de la interpretación textual, según opinión de los oyentes, con un excesivo análisis del griego y el hebreo. En el curso 1532-1533 tenía 100 oyentes, los mismos que tenía Juan de Medina en Nominales. Son interesantes los testimonios de los estudiantes del primer curso de Biblia en Alcalá: Bernardo de Zurbarán, colegial del M ayor, dijo «lee el II de las Epistola ad Romanos y que no pasaba mucho y que se detiene en textos griegos en cosas superfluas», Miguel Gómez, colegial del Mayor, dijo que "se detiene mucho e passa pero no haze algo, es superfluo en griego y hebraico» o el maestro Rodrigo de la Fuente dijo «que no repassa nada». Para el curso 1534-1535, bajó a 70 su auditorio, y hay otro detalle respecto a las lecturas en las que se detenía: Fr. Pedro de Peralta dijo «que lee el cap. 11 de San Juan e suele tener hasta 70 oyentes e suele faltar por su enfermedad y en tiempo de cuaresma. En lo demás todos contentos».

Enfermo, pasa a Toledo en 1536 en que le sustituye Jorge de Naveros, que no accede a la oposición hasta $1539^{90}$ a quien ya vimos intentando acceder a Santo Tomás siendo regente de Artes en 1529. Estuvo muy bien considerado ${ }^{91}$ y subió la audiencia de la cátedra hasta los ciento cincuenta oyentes, incluso llegó a tener trescientos un solo curso. Aunque estaban contentos con él, los estudiantes indican que se quedaba más en cuestiones escolásticas o cábala cristiana que en los textos de la Biblia o las cartas a San Pablo, que demandaban. Algo por lo que es multado en 1540. En 1539-1540 tenía ya 200 oyentes fray Francisco de Ajofrín OFM dijo «que no declara la Epta. ad Romanos y no ha acabado el $p$ o y que le parece que no lee al propósito de San Pablo ni Sagrada Escritura sino cuestiones escolásticas que se presuponen que se saben ya los oyentes y pasa poco texto», fray Luis de Valencia OFM «dijo que trahe muchas escolásticas y que no passa texto», Francisco de la Peña «acerca de la letra de San Pablo que no entra mucho en ella y se tarda y lee questiones que no hacen a la materia y algunas veces se extiende más de lo que es menester e no resuelve» y Diego Pérez «que repite muchas veces las cosas». Al final de la visita indica una apostilla "terminose que el Sr. Rector hable al doctor Naveros porque cure questiones escolásticas, sino que passe más exponiendo conforme a los términos antiguos». De las visitas de sus aulas en el curso 1540-1541 fray Francisco Verdugo, OFM ${ }^{92}$ «lee a San Juan en el capítulo octavo. Suele haber más de ciento y cincuenta oyentes y que comentó a San Juan el año pasado y que le parece que no passa mucho y que se detiene en algunas cuestiones escolásticas y que está contento». Fray Pedro de Herrera dijo «que lee el Dr. Naveros el psalmo

90 Se elige como canciller universitario en noviembre de 1541 al estar enfermo el abad de San Justo y ausente el tesorero, ya que habían de celebrarse exámenes de Teología y no podían retrasarse. Ver Libro de actos y grados, AHN, Universidades, Libro 397, folio 144r. Entró colegial de San Ildefonso en junio de 1524. Ver nota 57.

91 Gómez de Castro 1984: 546-547. En el curso 1527-1528 fue acusado de ser descendiente de conversos por Juan Sánchez de Ayora, que a su vez había sido acusado por Naveros. Ver Papeles varios sobre la Universidad y colegios de Alcalá, I, AHN, Universidades, Libro 1222, folios 123-126.

92 Beltrán de Heredia (1973: 156) no indica las lecturas de Naveros del curso 1540-1541, que es el Evangelio de San Juan. e que no lea tanto griego ni hebreo porque no hay quien lo entienda», al igual que el maestro Antezana que indicó «sería mejor que passase más».

\section{ESTADO DE CÁTEDRAS MENORES DE TEOLOGÍA}

Se proveyeron las primeras cátedras menores de Santo Tomás, Escoto y Durando (menor de Nominales) en octubre de $1536^{93}$ accediendo: fray Domingo de Santa Cruz, OP, a la menor de Santo Tomás; a la menor de Escoto Miguel del Arco y a la de Durando Juan de Angulo. Aunque vamos a ver que apenas hay referencias en las visitas de aulas a estas cátedras menores, consideramos que es útil una breve descripción de sus regentes, por cuánto aportaban la estabilidad en cursos de los que las cátedras mayores adolecían.

\section{Cátedra menor de Santo Tomás}

Fray Domingo de la Cruz OP, como vimos en la cátedra de prima tomista, era Pedro Hernández de Saavedra, rector de Alcalá en 1524-1525. Permanece cuatro cursos como regente de la menor hasta 1539-1540 de los que apenas hay referencias, salvo en este último curso en que fray Jorge de Oliz OFM dijo "del Maestro fraile lee la secunda secundae del principio y que todos están contentos» y el bachiller Helgueta dijo «del Fraile ha de decir que Velasco dice que trae las materias algo extrañas y que de todos están contentos». Le sustituye Miguel de Torres el cual accede a la regencia de la menor de Santo Tomás en febrero de 1540 para permanecer tan solo unos meses. ${ }^{94}$ No hay constancia de testigos de los meses que actúa como regente. Tras él accede Pedro Martínez Núñez en septiembre de 1540 hasta 1544. Apenas hay referencias a este teólogo. Alcanzó a tener treinta oyentes leyendo a Santo Tomás. Así, en el curso 1540-1541, Pedro Ibáñez dijo «que lee la prima secundae y que tiene hasta $x x x$ oyentes y que no siente falta en él» y el licenciado Belabrarán «dijo que oye al doctor Martínez y que le ha contentado en las lecciones».

\section{Cátedra de Durando o menor de Nominales}

Comenzó Juan de Angulo ${ }^{95}$ en 1536-1537. Apenas hay referencias a él en las visitas de cátedra, ni tampoco en los

93 Libro de actos y grados 1544-1562, AHN, Universidades, Libro $398 \mathrm{~F}$, folio 89 r.

${ }_{94}$ Fue maestro en Artes y doctor en Teología. En septiembre de ese mismo año pasa a Roma como procurador de las causas de San Ildefonso, en la pugna por el fuero universitario y reforma contra Tavera. Torres, tras cinco años al servicio de San Ildefonso, pasa a la Compañía de Jesús en 1546. Del colegio de Alcalá, fundado en 1543 y primera fundación colegial de los jesuitas, parte para fundar él mismo el de Salamanca. En López Pego 2009: 159-190. En el Libro de actos de la Facultad de Teología, AHN, Universidades, Libro 396F, folio 61, el 26/ XII/1537 se reúne la Facultad de Teología sobre varios asuntos entre ellos: «Determinatu fuit Mag. Michael de Torres faciat suam magnam ordinarium ante 12 allendas novembris \& dispensatum fuit cum illo». Para conocer la orden en el XVI ver Bataillon 2010.

95 No confundir con Iñigo de Angulo quien, en el curso 1537-1538 accede a la Facultad de Teología como doctor del claustro. Realiza, en 1540, una donación de casas que tenía entre el Postigo de los Judíos y la Puerta Angulema para el Hospital de estudiantes citado en Libro copiador de cartas, recibís de misas y ausencias y presencias, AHN, Universidades, Libro 676, folios sin numerar 
actos de la Facultad de Teología. En el curso 1539-1540 el bachiller Calvo dijo que estaba contento con sus lecciones. Le siguió Martín Malo, ${ }^{96}$ que fue regente de la cátedra de Durando hasta $1542-1543$ y a quien ya vimos como estudiante en 1526 opinando sobre la regencia de Matatigui. Todos estaban contentos como el testimonio de Pedro Ibáñez dijo «que oye al doctor Martín Malo que lee a Durando el 1. y la Dicción y que tiene hasta cincuenta oyentes o más y que está contento de su lectura y que lee a sabor de los oyentes». Blas de Alcocer es quién finaliza nuestro periodo ya que es proveída la cátedra de Durando en octubre de $1543 .{ }^{97}$ No hay referencias de él en las visitas de cátedra.

\section{Cátedra menor de Escoto}

Comenzó Miguel del Arco el curso 1536-1537, no hay registro de visitas pues Francisco de Vera accedió el curso siguiente. De su etapa como regente no queda constancia en las visitas de aulas. Tras él, Pablo Velázquez de Montemayor accede en enero de 1540. Había sido regente de Artes entre 1534-1535 hasta 1537-1538. Se doctora en Teología en julio de 1536. Apenas hay referencias a él en las visitas de aulas como la del bachiller Calvo dijo «que está contento salvo que falta algunas vezes y viene tarde a leer». Le sigue Diego Lópe $z^{98}$ en octubre de 1540 del cual indicaron en 1541-1542 fray Francisco Verdugo OFM «dijo que lee bien y se declara y que lee el 2. a de Escoto y tiene XX o XXX oyentes y que le contenta y que no hay falta en él. Que la falta que hay es que se proveyese la cátedra de Santo Tomás principal». Finaliza nuestro periodo Pedro Sánchez Zumel que oposita en octubre de 1543, sin testimonios de sus oyentes.

\section{CONCLUSIONES}

Como vemos en el Cuadro 3, Cisneros dejó establecidas las visitas ordinarias y de cátedra como mecanismo de control a la Universidad de Alcalá. Las de aulas, además, tuvieron su origen en el conocimiento de la calidad de la docencia. Para ello, los rectores y consiliarios interrogaban cada curso a estudiantes, testigos de las aulas complutenses. Reflejaban los testimonios jurados en actas, las cuáles debían derivarse al visitador ordinario de San Justo quien, en enero y julio de cada curso, analizaba la situación de la universidad y observaba el estado de las cátedras.

96 Interesantes datos biográficos, con resumen de su paso por Alcalá y actuaciones en el Concilio, en Gutiérrez 1951: 761-762; Rubio Fuentes 2010. Se doctora en Teología en marzo de 1535 y accede a la de Durando como regente en enero de 1540. Participó en Trento como teólogo de don Cristóbal de Rojas, con quien trabó amistad en los años que coincidieron en San Ildefonso. En Alcalá pasó de estudiante de Artes a Maestro, regente de Artes entre $1533-1534$ y 1536-1537, rector y colegial de San Ildefonso, doctor en Teología, canónigo de San Justo.

97 Registro de escrituras ante los escribanos contadores de la hacienda y rentas del Colegio Mayor de San Ildefonso, AHN, Universidades, Libro 6F, folios 322-325. Es doctor en Teología un año antes, en diciembre 1542. Regente de Artes, colegial del Mayor, donó -en su testamento- parte de su legado a la Universidad de Alcalá.

98 Obtiene el doctorado en Teología en diciembre de 1542 en el mismo curso en el que acceden Andrés de la Cuesta, Zumel o Blas de Alcocer. No preside ningún acto académico en este período.

\section{CUADRO 3}

El control de la Universidad de Alcalá por medio de las visitas LAS VISTTAS A LA UNIVERSIDAD DE ALCALÁ SEGÚN CONSTITUCIONES

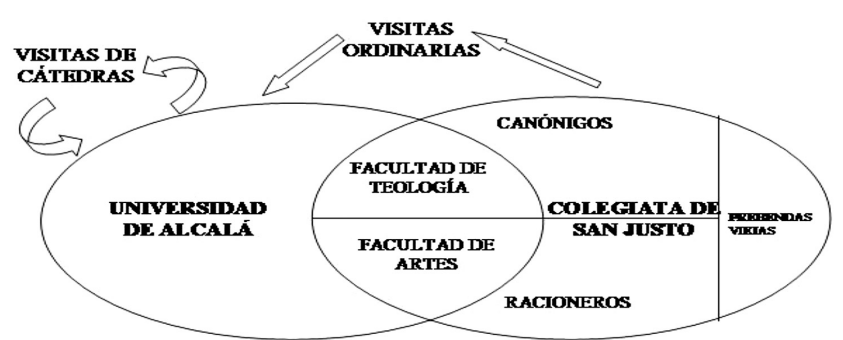

Fuente: elaboración propia.

Así, del estudio presentado, podemos extraer las siguientes conclusiones:

- La rotación efectiva de los regentes respecto a la teórica, que podemos ver en el Cuadro 4. Las regencias duraban 4 años, por tanto, los regentes teóricos deberían ser aquellos que hubieran permanecido esos 4 años o más al frente de una cátedra. Rotaciones por encima del $100 \%$ nos indican que hubo más regentes de lo esperado, es decir, que no acababan sus cuatro años de regencia.

CUADRO 4

Rotación efectiva de regentes teólogos de la Universidad de Alcaló

\begin{tabular}{|c|c|c|c|c|c|}
\hline & $1524-1534$ & $1534-1544$ & TOTAL & $\begin{array}{c}\text { Rotación } \\
\text { teórica por } \\
\text { cátedra }\end{array}$ & $\begin{array}{c}\text { Rotación } \\
\text { efectiva por } \\
\text { cátedra }\end{array}$ \\
\hline TEOLOGÍA & & & & & \\
\hline & & & & & \\
\hline STO. TOMÁS & 6 & 6 & 12 & 5 & $12 / 5 * 100=240 \%$ \\
\hline ESCOTO & 4 & 2 & 6 & 5 & $120 \%$ \\
\hline NOMINALES & 1 & 1 & 1 & 5 & $20 \%$ \\
\hline MENOR STO. TOMÁS & 0 & 4 & 4 & 2,5 & $160 \%$ \\
\hline MENOR ESCOTO & 0 & 4 & 4 & 2,5 & $160 \%$ \\
\hline DURANDO & 0 & 3 & 3 & 2,5 & $120 \%$ \\
\hline BIBLIA & 1 & 2 & 3 & 3 & $100 \%$ \\
\hline
\end{tabular}

Fuente: elaboración propia.

- La principal cátedra, la tomista, es la que más rotación presenta de todas con un $240 \%$, es decir, más del doble de lo esperado, según vemos en el Cuadro 4. Tal variedad de regentes, lejos de construir una Escuela con las particularidades de cada catedrático, suponía en primer lugar falta de unidad doctrinal en la lectura de la materia. En las actas, los estudiantes se quejan de no haber lecturas durante meses, que se leían proposiciones de Erasmo y no del doctor angélico y otras cuestiones varias. Poco antes de la llegada del dominico Melchor Cano se regularizaron las lecturas, hasta entonces a criterio del regente, imponiendo, ya con los dominicos, la lectura de cuatro años completa de la Secunda secundae. Fue la base de la renovación teológica que ya hubo revitalizado Francisco de Vitoria en Salamanca. 
- Hubo periodos de tiempo que incluso no hubo regente, ni tampoco el Colegio Mayor, administrador y gobierno de la Universidad, se preocupó de proveerla como denunció el visitador real Francisco de Navarra en 1534. Los regentes, a su vez, tenían otras ocupaciones, viajaban o se marchaban a otros puestos en la burocracia o buscaban la carrera eclesiástica. En el Cuadro 5 se observan periodos sin oyentes por este motivo.

\section{CUADRO 5}

Evolución de oyentes a las aulas teológicas de la Universidad de Alcaalá según las visitas de cátedras
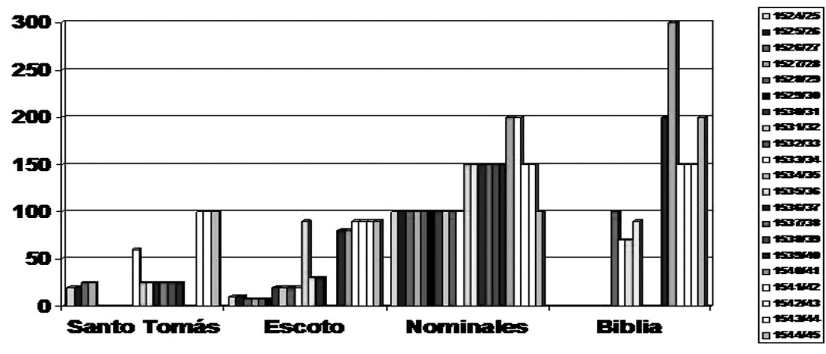

Fuente: elaboración propia.

- La injerencia externa afectó a la estabilidad prevista por constituciones: la creación de una política clientelar en Alcalá por parte del arzobispo Fonseca y el abad Pedro de Lerma, el secretario y testamentario Miguel Carrasco y Pedro Ciruelo. Ellos eran los teólogos más antiguos y los que controlaban no solo la Facultad de Teología sino las canonjías nuevas en San Justo.

- De hecho, la clara injerencia de Fonseca se advierte en el acceso de Juan Egidio y Pedro Alexandre a la rectoría y a la cátedra tomista, así como en el manejo de las licencias teológicas a merced de Ana de Ulloa, enviada de Fonseca en sus ausencias de Alcalá, para controlar los nuevos nombramientos. Cabe destacar otro detalle importante: la construcción de un modelo. En diez años Alcalá pasó de tener un regente de Santo Tomás que fue clandestinamente luterano -Juan Egidio-, a dirigir esa misma cátedra fray Melchor Cano OP, patológicamente ortodoxo.

- Tampoco el Escotismo, otra apuesta de Cisneros para la orden franciscana, aportó nada en este período. Los regentes, aunque con menos rotación, fueron mediocres docentes. Fernando de Burgos/Matatigui, Francisco de Vargas y Diego de Naveros destrozaron la cátedra escotista en los fundamentales primeros treinta años de vida. A Diego de Naveros tardaron 3 cursos en multarle, demasiado tarde para atraer estudiantes. Tampoco hubo unidad doctrinal en la cátedra escotista ya que hubo cursos enteros en que no se leyó a Escoto en contra de la constitución 43.

- Cuando Diego Laínez finaliza Artes en Alcalá, en 1532, las cátedras teológicas complutenses distan de ser atractivas: Santo Tomás sin titular durante varios meses y con la problemática suscitada entre Pedro Alexandre y Juan de Angulo frenando las licencias teológicas de los contrarios. Tampoco es que fuera atractiva la regencia de Escoto de Francisco de Vargas, con 20 oyentes. De hecho, Laínez no fue el único teólogo de Trento que no estudió teología en Alcalá sino solo Artes. Salvo Martín Malo, que se doctora en 1534, el resto de los teólogos doctores que aportó Alcalá a Trento y que estudiaron teología en la universidad de Cisneros fueron 10. Comenzaron a quedarse y doctorarse cuando se estabilizan las cátedras como, por ejemplo: Pedro Zumel y Andrés de la Cuesta en 1542, Francisco Trujillo en 1555, Diego Sobaños en 1558 o Cardillo de Villalpando en 1559.

- Las visitas a las cátedras mostraron su inutilidad al no reparar ni atender a tiempo faltas de lectura, ausencias, debilidades y pobres auditorios. Además, desde 15251526 los visitadores ordinarios denunciaron que ni el rector ni los colegiales asistían a misa, ni al oficio divino. $\mathrm{Ni}$ siquiera al rezo de la Salve. Algo de lo que se haría eco el visitador real Francisco de Navarra en 1533 y aún Juan de Quiñones, también enviado regio, en 1544.

- Respecto al Cuadro 5 que son los oyentes de las aulas teológicas entre 1524 y 1545 podemos ver que los del tomismo fueron como mucho sesenta estudiantes hasta Melchor Cano en que llegaron a la centena. Había cursos, como los de Jerónimo Velasco, en que el número de los asistentes fue de 25. En Escoto con Diego de Naveros, ni 10. El resto habían incrementado el auditorio de Juan de Medina que pasó de 100 a 150. Por tanto, hay una clara inestabilidad en la cátedra tomista complutense en el período 1524-1534 y que, además, coincide con el arzobispado de Alonso III de Fonseca en Toledo. En Escoto no fue hasta 1534 en que se pasó de 8 y 10 oyentes a los 80 . En las dos primeras décadas de nuestro estudio apenas asistirían al aula escotista los franciscanos del colegio de San Pedro y San Pablo, pero ningún otro oyente ni colegial ni estudiante libre.

- Hay registrados una cifra aproximada a los cien testigos de aulas teológicas en las fuentes del AHN. Aún con la baja presencia entonces de colegios regulares, la mitad de los testigos son frailes mendicantes $y$, de estos, casi en su totalidad franciscanos. Por la lectura del resto de visitas de aulas sabemos que también hay agustinos, trinitarios, de San Pablo eremita y cistercienses. Cabe destacar la inexistencia de oyentes dominicos, al menos solo a uno en el curso 1539-1540, teniendo en cuenta que el colegio convento de Santo Tomás vinculado a la Universidad de Alcalá es de 1529 (fundado por Carlos de Mendoza, deán de la catedral de Toledo). El medio centenar restante lo componen licenciados y bachilleres teólogos, antes que maestros en Artes. Por tanto, los visitadores primaban el clero regular y la antigüedad de los estudiantes para elegir a los testigos de las aulas.

- Por otro lado, respecto al ideal cisneriano de oír las tres cátedras de forma conjunta por los estudiantes, recogida en la constitución 43 , sabemos que no se cumplió. Así, de los testigos de las visitas de aulas, conocemos que un $40 \%$ declararon oír una sola cátedra, $25 \%$ oyeron dos, otro $25 \%$ oían las tres cátedras de Prima y solo el $10 \%$ oyeron todas incluyendo la de Biblia. Las ausencias, las faltas y la poca calidad que hemos visto en los regentes fueron las causantes de estas decisiones estudiantiles.

- Las vacaciones, además, suponían un corte durante el mes y medio que duraban, y los regentes no tenían tiempo para acabar sus cursos, retrasando cada lectura. 
- Las cátedras menores ofrecieron cierto equilibro desde su aparición en 1536, toda vez que servían para que aquellos que aspirasen a una cátedra de Prima tuvieran un fiel auditorio.

\section{FUENTES}

Beltrán de Heredia, Vicente. 1974. Cartulario de la Universidad de Salamanca VI. Salamanca: Universidad de Salamanca.

Caballero, Fermín. 1871. Vida del Ilmo. Sr. D. Fray Melchor Cano del Orden de Santo Domingo. Madrid: Imprenta del Colegio de Sordomudos.

Dalmases, Cándido de (ed.). 1977. «Processus Complutenses de Sancti Ignatii sociorumque vita et doctrina». En Fontes documentales de S. Ignacio de Loyola. Col. Monumenta Histórica S. I. 115, 319-349. Roma: Institutum historicum Societatis lesus.

Encinas, Francisco de. 1992. Memorias. Madrid: Clásicas.

Fita, Fidel. 2007. Los tres procesos de San Ignacio de Loyola. Alicante: Biblioteca Virtual Miguel de Cervantes [Edición digital a partir de Boletín de la Real Academia de la Historia, 1898, tomo 33: 422 461]. http://www.cervantesvirtual.com/obra/los-tres-procesosde-san-ignacio-de-loyola-en-alcal-de-henares-estudio-crtico-0/

Flórez, Enrique. 1795. España Sagrada, tomo XXXIX. Madrid: Viuda e hijo de Marín.

García Oro, José y Portela Silva, María José. 1999. Los Reyes y la Universidad de Alcalá en el S. XVI. Visitas reales. Liceo Franciscano 154-156. Santiago de Compostela: El Eco Franciscano.

García Oro, José y Portela Silva, María José (coords.). 2006. Visitas ordinarias a la Universidad de Alcalá de Henares en el siglo XVI. Liceo Franciscano 175-177. Santiago de Compostela: El Eco Franciscano.

Gómez de Castro, Álvar. 1984. De las hazañas de fray Francisco Jiménez de Cisneros. Trad. J. Oroz Reta. Madrid: Fundación Universitaria Española.

González Montano, Reinaldo. 2010. Artes de la Inquisición española. Reedición de 1851 de Sanctae Inquisitionis Hispanicae artes aliquot detectae, Heidelberg, 1567. Madrid: Almuzara.

González Navarro, Ramón. 1984. Universidad Complutense. Constituciones originales cisnerianas. Alcalá de Henares: Ediciones Alcalá.

Gutiérrez Torrecilla, Luis Miguel. 2014. «Fuentes documentales y archivos para el estudio de la Universidad de Alcalá». En Fuentes, archivos y bibliotecas para una historia de las universidades hispánicas. Salamanca: Universidad de Salamanca.

Hazañas y La Rúa, Joaquín. 1890. Maese Rodrigo. Sevilla: Librería de Izquierdo y Cía.

Paz y Meliá, Antonio y Manuel Serrano Sanz. 1902. «Actas originales de las juntas celebradas en Valladolid en 1527 para examinar las doctrinas de Erasmo». Revista de Archivos, Bibliotecas y Museos VI: 60-73.

Tellechea Idigoras, José. 1962. Fray Bartolomé de Carranza. Documentos históricos. Madrid: RAH.

\section{BibLIOGRAFÍA}

Abellán García, José Luis. 1976. El erasmismo español. Una historia de la otra España. Madrid: Espejo.

Alvar Ezquerra, Alfredo. 2010. El Duque de Lerma. Corrupción y desmoralización en la España del siglo XVII. Madrid: La esfera de los libros.

Alvar Ezquerra, Alfredo. 2010. «La Universidad de Alcalá en el siglo $\mathrm{XV} \mid »$. En Historia de la Universidad de Alcalá, coordinado por Antonio Alvar Ezquerra. Alcalá: Universidad de Alcalá.

Bataillon, Marcel. 1950. Erasmo y España. Buenos Aires: Fondo de Cultura Económica.

Bataillon, Marcel. 2010. Los jesuitas en la España del siglo XVI. Valladolid: Junta de Castilla y León.

Belda Plans, Juan. 1982. "La autoridad del Romano Pontífice según Melchor Cano, en los comentarios inéditos a la II-II, q. 1, a. 10». Scripta theologica: revista de la Facultad de Teología de la Universidad de Navarra 14 (1): 59-103.
Beltrán de Heredia, Vicente. 1960. Domingo de Soto. Estudio biográfico documentado. Salamanca: Biblioteca de teólogos españoles.

Beltrán de Heredia, Vicente. 1972. Miscelánea Beltrán de Heredia II. Salamanca: Universidad de Salamanca.

Beltrán de Heredia, Vicente. 1973. Miscelánea Beltrán de Heredia IV. Salamanca: Universidad de Salamanca.

Boeglin, Michel. 2005. «Evangelismo y sensibilidad religiosa en la Sevilla del quinientos: consideraciones acerca de la represión de los luteranos sevillanos». Studia Histórica 27: 163-189.

Carrasco Tezanos, Ángel. 2016. A voz de Comunidad. Rebelión comunera en Alcalá. 1520-1521. Alcalá de Henares: Domiduca Libreros.

Casado Arboniés, Manuel y Román Pastor, Carmen. 2017. Fundadores y Patronos. Alcalá de Henares siglo XVI. Alcalá de Henares: Universidad de Alcalá.

Denis, Philippe. 1977. «Pierre Alexandre et la discipline Ecclésiastique». Bibliothèque d'Humanisme et Renaissance 39: 3.

Díaz de la Guardia López, Luis. 2011. «El derecho castellano y la búsqueda del escribano perfecto (siglo XVI)». En El notariado andaluz: institución, práctica notarial y archivos: siglo XVI, 15-38. Granada: Universidad de Granada.

Fernández, Cecilia. 2001. La biblioteca de la Universidad Complutense (1508-1836). Tesis doctoral, Universidad Complutense. http:// eprints.ucm.es/43085/1/T25110.pdf

García Villoslada, Ricardo. 1938. La Universidad de París durante los estudios de Francisco de Vitoria. Roma: Universitá Gregoriana.

Gilly, Carlos. 1983. "Juan de Valdés: Übersetzer und Bearbeiter von Luthers Schriften in seinen Dialogo de Doctrina». Archiv für Reformationsgeschichte 74: 257-305. https://doi.org/10.14315/ arg-1983-jg12

Gutiérrez, Constancio. 1951. Españoles en Trento. Valladolid: Instituto Jerónimo Zurita.

Hernández Martín, Ramón. 2010. «Melchor Cano antes de su profesorado en Salamanca». Ciencia Tomista 137 (442): 381-442.

Hernández Sandoica, Elena y Peset, José Luis. 1993. Universidad, poder académico y cambio social (Alcalá de Henares 1508-Madrid 1874). Madrid: Consejo de Universidades.

León de la Vega, Manuel de. 2011. Los Protestantes y la espiritualidad evangélica del siglo XVI. Oviedo: León de la Vega.

López Pego, Carlos. 2009. «El inusitado y extraño fenómeno vocacional de los estudiantes de la Universidad de Alcalá hacia la Compañía de Jesús». Hispania Sacra 123: 159-190. https://doi.org/10.3989/ hs.2009.v61.i123.84

Luttikhuizen, Frances. 2017. Underground Protestantism in Sixteenth Century Spain. A Much Ignored Side of Spanish History. Göttingen: Vandenhoeck + Ruprecht.

Maravall, José Antonio. 1972. La oposición política bajo los Austrias. Barcelona: Ariel.

Moreno Trujillo, María Amparo. 2011. «La conflictividad de los escribanos en el ejercicio de sus funciones». En El notariado andaluz: institución, práctica notarial y archivos: siglo XVI, 15-38. Granada: Universidad de Granada.

Morocho Gayo, Gaspar. 2013. "Hermetismo y cábala cristiana en la corte de Carlos V: Egidio de Viterbo, Dionisio Vázquez, Cipriano de la Huerga». Ciudad de Dios 3: 813-854.

Muñoyerro, Luis. 1945. La Facultad de Medicina de la Universidad de Alcalá. Madrid: CSIC.

Rodríguez Suárez, María del Pilar. 2003. «Escribanos y documentos universitarios del siglo XVI en la Universidad de Santiago de Compostela». Aulas y saberes 2: 419-434.

Rubio Fuentes, María José. 2010. "Martín Malo. La Universidad Complutense y el Concilio de Trento». Anales Complutenses 22: 147-166.

Sendín Calabuig, Manuel. 1977. El Colegio Mayor del Arzobispo Fonseca en Salamanca. Salamanca: Universidad.

Torre y del Cerro, Antonio de la. 1925. "La Universidad de Alcalá. Estado de la enseñanza según las visitas de cátedras de 152425 y 1527-28». En Homenaje ofrecido a Menéndez Pidal, vol. III. Madrid: Librería Hernando.

Urriza, Juan. 1941. La preclara Facultad de Arte y Filosofía de la Universidad de Alcalá 1509-1621. Madrid: CSIC. 